\title{
Hyperoxemia and excess oxygen use in early acute respiratory distress syndrome: insights from the LUNG SAFE study
}

Fabiana Madotto ${ }^{1,2}$, Emanuele Rezoagli ${ }^{3,4,5}$, Tài Pham ${ }^{6,7,8}$, Marcello Schmidt $^{9}$, Bairbre McNicholas ${ }^{10}$, Alessandro Protti ${ }^{11,12}$, Rakshit Panwar ${ }^{13,14}$, Giacomo Bellani ${ }^{3,15}$, Eddy Fan ${ }^{4,8,9,16}$, Frank van Haren ${ }^{17}$, Laurent Brochard ${ }^{6,7,8}$, John G. Laffey ${ }^{4,5,6^{*}}$ (D) for the LUNG SAFE Investigators and the ESICM Trials Group

\begin{abstract}
Background: Concerns exist regarding the prevalence and impact of unnecessary oxygen use in patients with acute respiratory distress syndrome (ARDS). We examined this issue in patients with ARDS enrolled in the Large observational study to UNderstand the Global impact of Severe Acute respiratory FailurE (LUNG SAFE) study.

Methods: In this secondary analysis of the LUNG SAFE study, we wished to determine the prevalence and the outcomes associated with hyperoxemia on day 1, sustained hyperoxemia, and excessive oxygen use in patients with early ARDS. Patients who fulfilled criteria of ARDS on day 1 and day 2 of acute hypoxemic respiratory failure were categorized based on the presence of hyperoxemia $\left(\mathrm{PaO}_{2}>100 \mathrm{mmHg}\right)$ on day 1, sustained (i.e., present on day 1 and day 2) hyperoxemia, or excessive oxygen use ( $\mathrm{FIO}_{2} \geq 0.60$ during hyperoxemia).

Results: Of 2005 patients that met the inclusion criteria, 131 (6.5\%) were hypoxemic $\left(\mathrm{PaO}_{2}<55 \mathrm{mmHg}\right), 607$ (30\%) had hyperoxemia on day 1, and $250(12 \%)$ had sustained hyperoxemia. Excess $\mathrm{FIO}_{2}$ use occurred in $400(66 \%)$ out of 607 patients with hyperoxemia. Excess $\mathrm{FIO}_{2}$ use decreased from day 1 to day 2 of ARDS, with most hyperoxemic patients on day 2 receiving relatively low $\mathrm{FlO}_{2}$. Multivariate analyses found no independent relationship between day 1 hyperoxemia, sustained hyperoxemia, or excess $\mathrm{FIO}_{2}$ use and adverse clinical outcomes. Mortality was $42 \%$ in patients with excess $\mathrm{FIO}_{2}$ use, compared to $39 \%$ in a propensity-matched sample of normoxemic $\left(\mathrm{PaO}_{2} 55-100 \mathrm{mmHg}\right)$ patients $(P=0.47)$.
\end{abstract}

Conclusions: Hyperoxemia and excess oxygen use are both prevalent in early ARDS but are most often non-sustained. No relationship was found between hyperoxemia or excessive oxygen use and patient outcome in this cohort.

Trial registration: LUNG-SAFE is registered with ClinicalTrials.gov, NCT02010073

Keywords: Hyperoxia, Hypoxia, Hyperoxemia, Hypoxemia, Oxygen therapy, Acute respiratory distress syndrome, Mortality, Invasive mechanical ventilation

\footnotetext{
* Correspondence: john.laffey@nuigalway.ie

${ }^{4}$ Anaesthesia and Intensive Care Medicine, School of Medicine, National

University of Ireland Galway, Galway, Ireland

${ }^{5}$ Regenerative Medicine Institute (REMEDI) at CÚRAM Centre for Research in

Medical Devices, Biomedical Sciences Building, National University of Ireland Galway, Galway, Ireland

Full list of author information is available at the end of the article
}

\section{$\triangle B M C$}

(C) The Author(s). 2020 Open Access This article is licensed under a Creative Commons Attribution 4.0 International License, which permits use, sharing, adaptation, distribution and reproduction in any medium or format, as long as you give appropriate credit to the original author(s) and the source, provide a link to the Creative Commons licence, and indicate if changes were made. The images or other third party material in this article are included in the article's Creative Commons. licence, unless indicated otherwise in a credit line to the material. If material is not included in the article's Creative Commons licence and your intended use is not permitted by statutory regulation or exceeds the permitted use, you will need to obtain permission directly from the copyright holder. To view a copy of this licence, visit http://creativecommons.org/licenses/by/4.0/ The Creative Commons Public Domain Dedication waiver (http://creativecommons.org/publicdomain/zero/1.0/) applies to the data made available in this article, unless otherwise stated in a credit line to the data. 


\section{Key messages}

- Hyperoxemia and excess $\mathrm{FIO}_{2}$ use was prevalent in patients with early ARDS. Hyperoxemia occurred in $30 \%$ of patients, while two thirds of these patients received excess oxygen therapy.

- While a similar proportion of patients were hyperoxemic on day 2 of ARDS, higher $\mathrm{FIO}_{2}$ use did decrease. Consequently, most day 2 hyperoxemia was seen in patients at lower $\mathrm{FIO}_{2}$, in whom gas exchange was improving.

- In the majority of patients, both hyperoxemia and excess oxygen use were transient, although sustained hyperoxemia occurred in $12 \%$ of patients.

- Higher $\mathrm{FIO}_{2}$ use was independently associated with the risk of hyperoxemia, illustrating the need for close attention to oxygen use to reduce this risk.

- We found no relationship between the degree and duration of hyperoxemia or of excessive oxygen use, and outcome in early ARDS, in this patient cohort.

\section{Background}

Acute respiratory distress syndrome (ARDS) is a syndrome characterized by impaired gas exchange resulting in low oxygen tensions in the blood (i.e., hypoxemia) and tissues (i.e., hypoxia) [1]. Tissue hypoxia is harmful, leading to cell death, organ failure, and increased mortality in the critically ill [2]. While oxygen therapy can reverse tissue hypoxia, little evidence exists regarding the optimal use of oxygen in patients with ARDS. Critically ill patients frequently receive higher inspired oxygen concentrations than necessary [3], perhaps due to concerns regarding tissue hypoxia $[4,5]$.

Hyperoxemia and the resultant tissue hyperoxia may worsen systemic organ injury in the critically ill. Arterial hyperoxemia has been associated with increased mortality in some older [6-8] but not more recent $[9,10]$ studies of patients with acute brain injury. Hyperoxemia was associated with worse outcomes in cohort patients with acute ischemic stroke or subarachnoid/intracerebral hemorrhage that required invasive mechanical ventilation [11]. Supplemental oxygen therapy worsened myocardial injury and infarct size in patients post myocardial infarction [12]. In patients resuscitated post cardiac arrest, hyperoxia has been associated with harm in several [13-16] studies, although the most recent study [17] did not confirm this. Potential mechanisms of oxygen toxicity remain poorly understood and may include systemic arterial vasoconstriction $[18,19]$, and cytotoxic effects of reactive oxygen species [20-22]. In randomized trials, "induced" hyperoxia (using $100 \%$ oxygen) increased 28-day mortality in septic shock patients [23], while critically ill patients randomized to a target arterial oxygen tension $\left(\mathrm{PaO}_{2}\right)$ of $70-100 \mathrm{mmHg}$ had lower mortality compared to patients with a "conventional" target of $\mathrm{PaO}_{2}$ up to $150 \mathrm{mmHg}$ [24] in a single- center study. While a recent large international multicenter trial demonstrated no effect of conservative oxygen therapy in a diverse cohort of critically ill patients [25], a subsequent sub-study raised the possibility of clinically important harm with conservative oxygen therapy in patients with sepsis [26].

In ARDS, the relationship between oxygen use and outcome is complex. The severely impaired gas exchange means that high fraction of inspired oxygen $\left(\mathrm{FIO}_{2}\right)$ use may simply reflect a more severe alveolar-arterial oxygen gradient and hence be a marker of ARDS severity. In mild ARDS, relatively modest levels of $\mathrm{FIO}_{2}$ may result in (moderate) hyperoxemia and tissue hyperoxia. In addition, severe degrees of systemic hyperoxemia (i.e., $\mathrm{PaO}_{2}>300$ ) associated with harm in other critically ill populations are not possible in ARDS. However, even moderate systemic hyperoxemia that may be more commonly seen in ARDS could be harmful [27]. Furthermore, the use of high $\mathrm{FIO}_{2}$ can have direct toxic effects on the lung [28, 29], sensitize the lung to subsequent injury, adversely affect the lung innate immune response [30], and worsen ventilation-induced injury [31-33]. These complexities highlight the need to distinguish between hyperoxemia and high $\mathrm{FIO}_{2}$ use. In patients receiving high $\mathrm{FIO}_{2}$, it is important to determine whether this was necessary to achieve normoxemia or if it could have been avoided (i.e., excess oxygen use).

We wished to examine the impact of hyperoxemia and of excess oxygen use in this secondary analysis of patients with ARDS in the LUNG SAFE patient cohort [34]. Our primary objective was to determine the prevalence of early and sustained hyperoxemia and of excess oxygen use in patients with hyperoxemia. Secondary objectives included identifying factors associated with hyperoxemia and with excess oxygen use and examining the relationship between hyperoxemia and excess oxygen use and outcomes from ARDS.

\section{Methods \\ Design, setting, and participants}

This is a sub-study of the LUNG SAFE study, an international, multicenter, prospective cohort study of patients receiving invasive or noninvasive ventilation, and the detailed methods and protocol have been published elsewhere [34]. In brief, LUNG SAFE was an international, multicenter, prospective cohort study, with a 4week enrolment window in the winter season in both hemispheres [34]. National coordinators and site investigators obtained ethics committee approval and ensured data integrity and validity.

Given the study focus on early hyperoxemia and excess oxygen use, we restricted the study population to patients that fulfilled ARDS criteria within $48 \mathrm{~h}$ of ICU admission, and who remained in the ICU for at least 2 days from ARDS onset. Patients transferred from other 
ICUs after 2 days, patients that developed ARDS later in their ICU stay, and patients that received early ECMO were excluded (Fig. 1). Additional methodological details are available in Additional file 1.

\section{Data collection and analysis}

All data were recorded for each patient at the same time each day within participating ICUs, normally as close as possible to 10 a.m. each day. Data on ventilatory settings were recorded simultaneously with arterial blood gas analysis. The following definitions were applied on day 1 and on day 2 of ARDS: hypoxemia $\left(\mathrm{PaO}_{2}<55 \mathrm{mmHg}\right)$, normoxemia $\left(\mathrm{PaO}_{2} 55-100 \mathrm{mmHg}\right)$, and hyperoxemia $\left(\mathrm{PaO}_{2}>100 \mathrm{mmHg}\right)$. Excess oxygen use was defined as the use of $\mathrm{FIO}_{2} \geq 0.6$ in patients with hyperoxemia $\left(\mathrm{PaO}_{2}>100 \mathrm{mmHg}\right)$. Patients with hyperoxemia on days 1 and 2 of ARDS were considered to have sustained hyperoxemia. Analogously, we also defined patients with sustained hypoxemia and sustained normoxemia.

The duration of invasive mechanical ventilation (MV) was calculated as the number of days between the date of intubation and the date of extubation in ICU (or death, if the patient died under invasive MV). Similarly, invasive ventilator-free days were calculated as the number of days from weaning from invasive MV to day 28, and for patients who died before weaning, we considered to have a ventilator-free-day value of 0 . Patient survival was evaluated at hospital discharge, or at day 90, whichever occurred first. Our other data definitions have been previously reported [34-37].

\section{Statistical analyses}

Descriptive statistics included proportions for categorical and mean (standard deviation) or median (interquartile range) for continuous variables. No assumptions were made for missing data. To assess differences among three groups (systemic hypoxemia, normoxemia, and hyperoxemia), we performed chi-squared test (or Fisher exact test) for discrete variables and analysis of variance (ANOVA) (or Kruskal-Wallis test) for continuous variables. Bonferroni correction was applied to determine significance in the setting of multiple comparisons. Chi-square test (or Fisher exact test), Student's $t$ test (or Wilcoxon Mann Whitney test) were used to assess

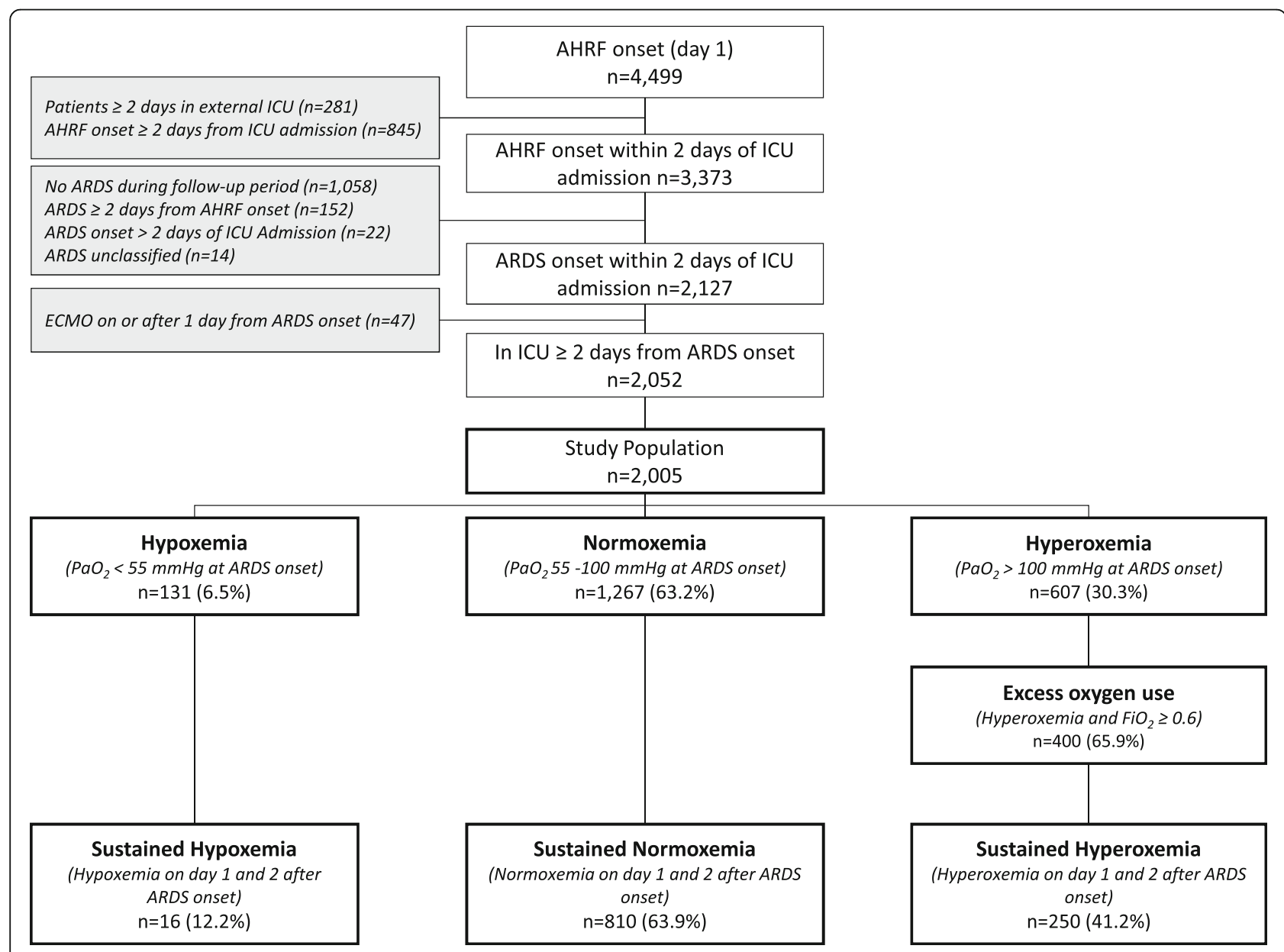

Fig. 1 Flow chart describing criteria used to select and to classify the ARDS study population 
differences between groups (i.e., sustained hyperoxemia and sustained normoxemia) in discrete and continuous distributions of parameters, respectively.

Locally estimated scatterplot smoothing (LOESS) method was used to inspect the relationship between mortality and $\mathrm{PaO}_{2}$ and $\mathrm{FIO}_{2}$ measured on day 1 and on day 2 of ARDS.

Multivariable logistic regression models were used to evaluate factors associated with the presence of either hyperoxemia or excess of oxygen use, and with mortality. In each regression model, the independent predictors (demographic characteristics and clinical parameters measured at the first day of ARDS) were identified through a stepwise regression approach. This approach combines forward and backward selection methods in an iterative procedure (with a significance level of 0.05 both for entry and retention) to select predictors in the final multivariable model. Results were reported as odds ratio (OR) with 95\% confidence interval (CI).

Propensity score matching method was applied to evaluate the possible impact of sustained hyperoxemia on main outcomes (mortality, ventilation-free days, and duration of MV) in patients with mild-moderate ARDS.
Patients with severe ARDS were excluded as there were no such patients in the sustained hyperoxemia group. In detail, patients with sustained hyperoxemia and sustained normoxemia were matched (1:1 match without replacement), using a caliper of 0.2 standard deviation of the logit of the propensity score, and the balance between the matched groups was assessed by the standardized differences of each independent variable used in the propensity score estimation. Statistical significance of the difference in continuous variables, as ventilation-free days and duration of MV, was evaluated with Wilcoxon signed-rank test, while for difference in proportions of deaths, we applied McNemar's test. Survival probability in these matched groups was estimated using the Kaplan-Meier approach and assuming that patients discharged alive from hospital before 90 days were alive on day 90. Statistical difference between survival curves was assessed through Kein and Moeschberger test. The same approach was used to assess the possible impact of excess use of oxygen on main outcomes.

All $p$ values were two-sided, with $p$ values $<0.05$ considered as statistically significant. Statistical analyses were performed with $R$, version 3.5.2. ( $R$ Project for
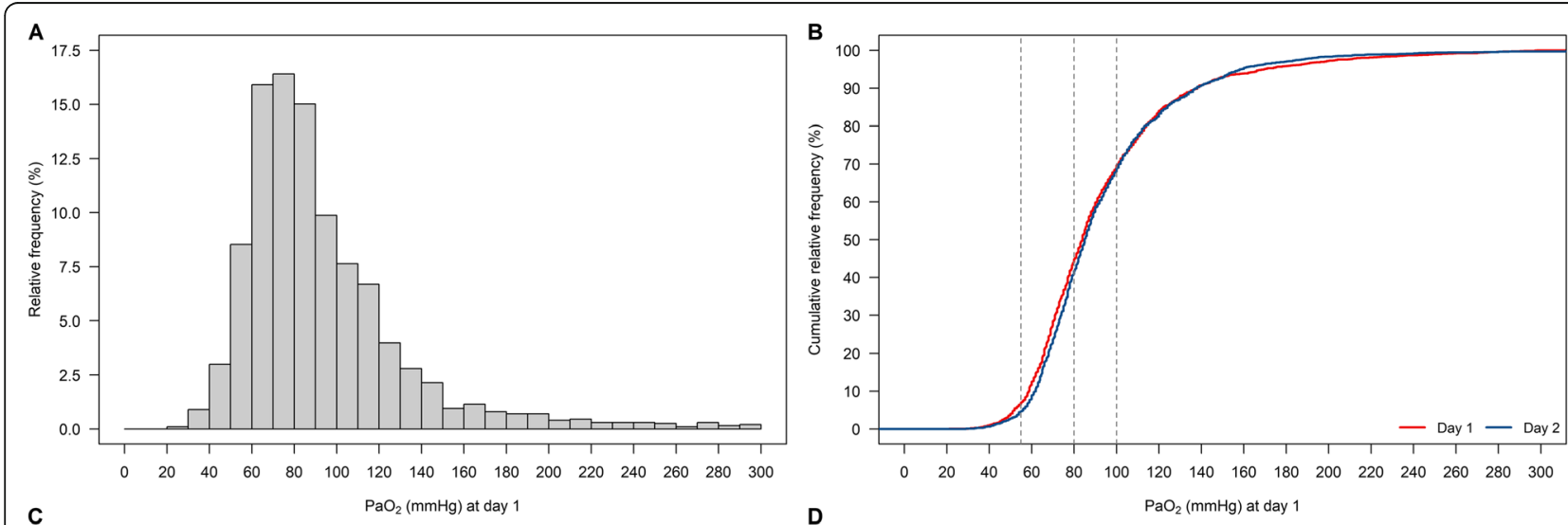

D
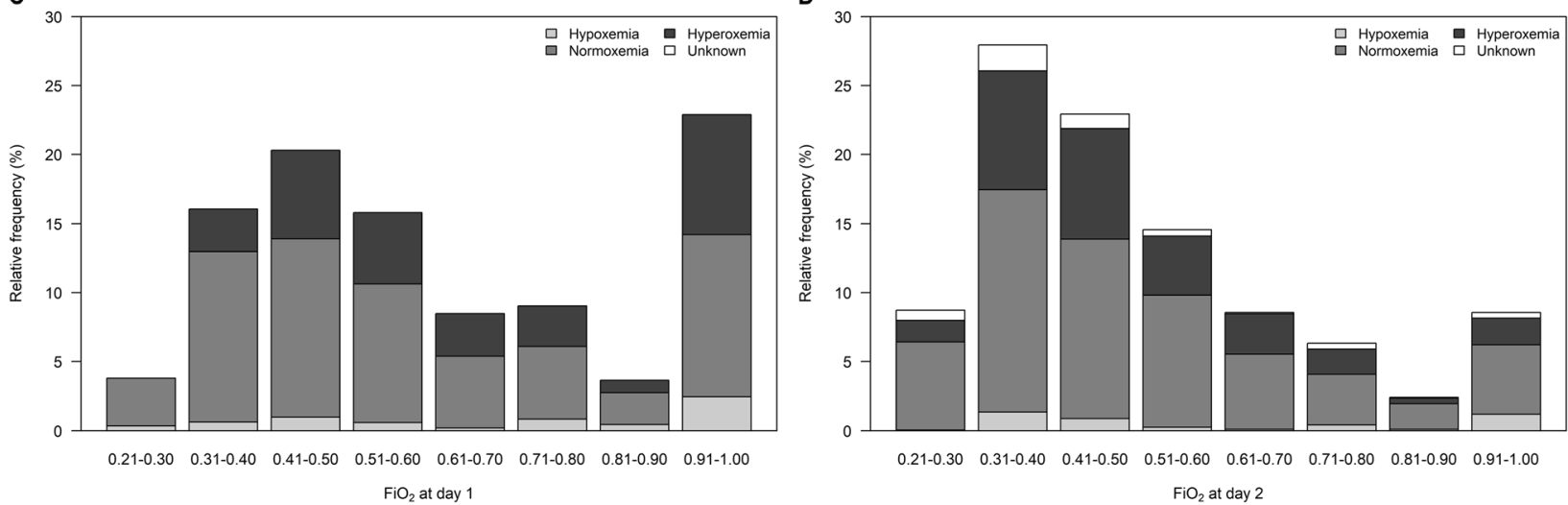

Fig. 2 Arterial oxygen tensions and use of oxygen in patients on days 1 and 2 of ARDS. a The distribution of $\mathrm{PaO}_{2}$ on day 1 of ARDS, demonstrating a wide range of $\mathrm{PaO}_{2}$. b Density distributions of $\mathrm{PaO}_{2}$ on days 1 (red line) and day 2 (blue line) of ARDS. c Histogram of $\mathrm{FIO}_{2}$ and $\mathrm{PaO}_{2}$ on day 1 of ARDS. $\mathbf{d}$ Histogram of $\mathrm{FIO}_{2}$ and $\mathrm{PaO}_{2}$ on day 2 of ARDS. Note: in $\mathbf{c}$ and $\mathbf{d}$, each bar is segmented into hyperoxemia (black), normoxemia (dark gray), hypoxemia (light gray), and unknown (white) component 
Table 1 Characteristics of study population $(n=2005)$, stratified by arterial oxygenation on day 1

\begin{tabular}{|c|c|c|c|c|}
\hline Parameter & $\begin{array}{l}\text { Hypoxemia } \\
\left(\mathrm{PaO}_{2}<55 \mathrm{mmHg}\right)\end{array}$ & $\begin{array}{l}\text { Normoxemia } \\
\left(55 \mathrm{mmHg} \leq \mathrm{PaO}_{2}\right. \\
\leq 100 \mathrm{mmHg})\end{array}$ & $\begin{array}{l}\text { Hyperoxemia } \\
\left(\mathrm{PaO}_{2}>100 \mathrm{mmHg}\right)\end{array}$ & $\begin{array}{l}p \text { value } \\
\text { (among groups) }\end{array}$ \\
\hline$N(\%)$ & $131(6.53)$ & $1267(63.19)$ & $607(30.27)$ & \\
\hline Male, $n(\%)$ & $73(55.73)$ & $796(62.83)$ & $359(59.14)$ & 0.1259 \\
\hline Age (years), mean $\pm S D$ & $59.20 \pm 16.86$ & $62.21 \pm 16.74$ & $61.88 \pm 16.82$ & 0.1264 \\
\hline $\mathrm{BMI}\left(\mathrm{kg} / \mathrm{m}^{2}\right)$, mean $\pm \mathrm{SD}$ & $27.23 \pm 6.82$ & $27.66 \pm 8.26$ & $26.90 \pm 6.84$ & 0.5646 \\
\hline \multicolumn{5}{|l|}{ ARDS risk factors, $n(\%)$} \\
\hline None & $9(6.87)$ & $103(8.13)$ & $52(8.57)$ & 0.8088 \\
\hline Only non-pulmonary & $15(11.45)$ & $229(18.07)$ & $106(17.46)$ & 0.1641 \\
\hline Only pulmonary & $92(70.23)$ & $769(60.62)$ & $357(58.81)$ & 0.0525 \\
\hline Both & $15(11.45)$ & 167 (13.18) & $92(15.16)$ & 0.3789 \\
\hline \multicolumn{5}{|l|}{ Illness severity at ARDS onset } \\
\hline $\mathrm{P}_{\mathrm{a}} \mathrm{O}_{2}(\mathrm{mmHg})$, mean $\pm \mathrm{SD}$ & $47.1 \pm 6.2$ & $76.8 \pm 11.9^{*}$ & $137.8 \pm 41.0^{*^{\dagger}}$ & $<0.0001$ \\
\hline $\mathrm{P}_{\mathrm{a}} \mathrm{O}_{2} / \mathrm{FIO}_{2}(\mathrm{mmHg})$, mean $\pm \mathrm{SD}$ & $75.12 \pm 38.97$ & $140.49 \pm 56.70^{*}$ & $205.90 \pm 54.88^{* \dagger}$ & $<0.0001$ \\
\hline $\mathrm{SpO}_{2}(\%)$, median $\left(\mathrm{q}_{1}-\mathrm{q}_{3}\right)$ & $88(82-94)$ & $95(92-97)^{*}$ & $98(97-99)^{*^{+}}$ & $<0.0001$ \\
\hline ARDS severity, $n(\%)$ & & & & $<0.0001$ \\
\hline Mild & $4(3.05)$ & $205(16.18)^{*}$ & $330(54.37)^{* \dagger}$ & $<0.0001$ \\
\hline Moderate & $22(16.79)$ & $683(53.91)^{*}$ & $273(33.98)^{*^{+}}$ & $<0.0001$ \\
\hline Severe & 105 (80.15) & $379(29.91)^{*}$ & $4(0.66)^{* \dagger}$ & $<0.0001$ \\
\hline $\mathrm{P}_{\mathrm{a}} \mathrm{CO}_{2}(\mathrm{mmHg})$, mean $\pm \mathrm{SD}$ & $54.3 \pm 25.0$ & $46.3 \pm 15.3^{*}$ & $44.8 \pm 14.6^{*}$ & 0.0031 \\
\hline $\mathrm{pH}$, mean $\pm \mathrm{SD}$ & $7.31 \pm 0.15$ & $7.33 \pm 0.12$ & $7.32 \pm 0.13$ & 0.7446 \\
\hline Bicarbonate $(\mathrm{mmol} / \mathrm{L})$, mean $\pm \mathrm{SD}$ & $26.3 \pm 10.9$ & $23.3 \pm 6.5$ & $22.3 \pm 6.3^{*}$ & $<0.0001$ \\
\hline Base excess $(\mathrm{mEq} / \mathrm{L})$, mean $\pm \mathrm{SD}$ & $0.5 \pm 10.8$ & $-2.0 \pm 6.8$ & $-3.1 \pm 6.8^{*^{\dagger}}$ & 0.0001 \\
\hline Non-respiratory SOFA score adjusted, mean \pm SD & $6.14 \pm 4.15$ & $6.08 \pm 3.94$ & $6.28 \pm 4.00$ & 0.6246 \\
\hline SOFA score adjusted, mean \pm SD & $10.25 \pm 4.20$ & $9.51 \pm 3.98$ & $8.87 \pm 3.93^{* \dagger}$ & 0.0005 \\
\hline Respiration & $3.79 \pm 0.46$ & $3.15 \pm 0.66$ & $2.45 \pm 0.50$ & $<0.0001$ \\
\hline Central nervous system & $1.68 \pm 1.72$ & $1.74 \pm 1.66$ & $1.92 \pm 1.69$ & 0.1161 \\
\hline Cardiovascular & $1.77 \pm 1.74$ & $2.03 \pm 1.76$ & $1.93 \pm 1.74$ & 0.1760 \\
\hline Liver & $0.65 \pm 0.98$ & $0.54 \pm 0.96$ & $0.51 \pm 0.92$ & 0.2855 \\
\hline Coagulation & $1.20 \pm 1.45$ & $0.95 \pm 1.31$ & $0.98 \pm 1.34$ & 0.1751 \\
\hline Renal & $0.69 \pm 1.04$ & $1.77 \pm 1.10$ & $0.88 \pm 1.22$ & 0.3333 \\
\hline \multicolumn{5}{|l|}{ Pressor support infusion rates } \\
\hline Dopamine $(\mu \mathrm{g} / \mathrm{kg} / \mathrm{min})$, mean $\pm \mathrm{SD}$ & $8.19 \pm 6.94$ & $8.58 \pm 5.02$ & $7.73 \pm 5.98$ & 0.4151 \\
\hline Dobutamine $(\mu \mathrm{g} / \mathrm{kg} / \mathrm{min})$, mean $\pm \mathrm{SD}$ & $5.52 \pm 3.74$ & $5.72 \pm 4.05$ & $6.75 \pm 3.53$ & 0.3565 \\
\hline Noradrenaline ( $\mu \mathrm{g} / \mathrm{kg} / \mathrm{min})$, mean $\pm \mathrm{SD}$ & $0.50 \pm 0.67$ & $0.45 \pm 0.75$ & $0.54 \pm 1.48$ & 0.6701 \\
\hline Adrenaline $(\mu \mathrm{g} / \mathrm{kg} / \mathrm{min})$, mean $\pm \mathrm{SD}$ & $1.10 \pm 2.03$ & $0.48 \pm 0.69$ & $0.43 \pm 0.55$ & 0.8434 \\
\hline \multicolumn{5}{|l|}{ Management factors at ARDS onset } \\
\hline Invasive mechanical ventilation, $n(\%)$ & $102(77.86)$ & $1000(78.93)$ & $506(83.36)$ & 0.0619 \\
\hline Control mode of ventilation, mean \pm SD & $70(54.69)$ & $693(55.89)$ & $386(64.23)^{\dagger}$ & 0.0021 \\
\hline $\mathrm{FIO}_{2}$, median $\left(\mathrm{q}_{1}-\mathrm{q}_{3}\right)$ & $0.80(0.50-1.00)$ & $0.60(0.41-0.80)^{*}$ & $0.65(0.50-1.00)^{\dagger}$ & $<0.0001$ \\
\hline $\mathrm{FIO}_{2} \geq 0.6, n(\%)$ & $90(68.70)$ & $670(52.88)^{*}$ & $400(65.90)^{\dagger}$ & $<0.0001$ \\
\hline $\mathrm{FIO}_{2} \geq 0.6$ at $2 \mathrm{nd}$ day, $n(\%)^{\ddagger}$ & $64(73.56)$ & $372(57.94)^{*}$ & $167(43.60)^{*^{\dagger}}$ & $<0.0001$ \\
\hline Tidal volume $(\mathrm{ml} / \mathrm{kg})$, mean $\pm \mathrm{SD}$ & $7.9 \pm 2.2$ & $7.8 \pm 2.0$ & $7.9 \pm 2.0$ & 0.2256 \\
\hline PEEP $\left(\mathrm{cmH}_{2} \mathrm{O}\right)$, mean $\pm \mathrm{SD}$ & $8.7 \pm 3.33$ & $8.1 \pm 3.2$ & $7.9 \pm 3.1^{*}$ & 0.0174 \\
\hline $\mathrm{PIP}\left(\mathrm{cmH}_{2} \mathrm{O}\right)$, mean $\pm \mathrm{SD}$ & $25.7 \pm 8.90$ & $25.3 \pm 8.5$ & $25.6 \pm 8.7$ & 0.6295 \\
\hline
\end{tabular}


Table 1 Characteristics of study population ( $n=2005)$, stratified by arterial oxygenation on day 1 (Continued)

\begin{tabular}{|c|c|c|c|c|}
\hline Parameter & $\begin{array}{l}\text { Hypoxemia } \\
\left(\mathrm{PaO}_{2}<55 \mathrm{mmHg}\right)\end{array}$ & $\begin{array}{l}\text { Normoxemia } \\
\left(55 \mathrm{mmHg} \leq \mathrm{PaO}_{2}\right. \\
\leq 100 \mathrm{mmHg})\end{array}$ & $\begin{array}{l}\text { Hyperoxemia } \\
\left(\mathrm{PaO}_{2}>100 \mathrm{mmHg}\right)\end{array}$ & $\begin{array}{l}p \text { value } \\
\text { (among groups) }\end{array}$ \\
\hline Dynamic compliance $\left(\mathrm{ml} / \mathrm{cmH}_{2} \mathrm{O}\right)$, mean $\pm \mathrm{SD}$ & $39.0 \pm 38.4$ & $36.9 \pm 37.8$ & $35.6 \pm 38.9$ & 0.7759 \\
\hline Total respiratory rate (breaths/min), mean \pm SD & $23.2 \pm 7.1$ & $21.9 \pm 6.9$ & $21.1 \pm 7.0$ & 0.0003 \\
\hline Standardized minute ventilation ( $\mathrm{L} / \mathrm{min})$, mean $\pm \mathrm{SD}$ & $14.4 \pm 7.8$ & $11.4 \pm 5.3^{*}$ & $10.8 \pm 5.0^{*}{ }^{\dagger}$ & $<0.0001$ \\
\hline Patients in whom plateau pressure measured, $n(\%)^{\circ}$ & $24(18.32)$ & $304(23.99)$ & $186(30.64)$ & 0.0012 \\
\hline Plateau pressure $\left(\mathrm{cmH}_{2} \mathrm{O}\right)$, mean $\pm \mathrm{SD}$ & $24.3 \pm 9.0$ & $23.4 \pm 6.1$ & $23.0 \pm 5.6$ & 0.7512 \\
\hline Driving pressure $\left(\mathrm{cmH}_{2} \mathrm{O}\right)$, mean $\pm \mathrm{SD}$ & $16.0 \pm 8.2$ & $14.6 \pm 5.4$ & $15.0 \pm 5.2$ & 0.4941 \\
\hline \multicolumn{5}{|l|}{ Clinical outcomes } \\
\hline Hospital mortality (90 days), $n$ (\%) & $47(35.88)$ & $486(38.54)$ & $227(37.52)$ & 0.7934 \\
\hline \multicolumn{5}{|l|}{ Ventilation free days (days), median $\left(q_{1}-q_{3}\right)$} \\
\hline All & $10.0(0.0-22.0)$ & $12.0(0.0-23.0)$ & $16.0(0.0-24.0)^{\dagger}$ & 0.0303 \\
\hline Survivors at ICU discharge & $20.0(14.0-24.0)$ & $21.0(15.0-25.0)$ & $23.0(18.0-26.0)^{*^{\dagger}}$ & 0.0002 \\
\hline \multicolumn{5}{|l|}{ Duration mechanical ventilation (days), median $\left(q_{1}-q_{3}\right)$} \\
\hline All & $7.0(4.0-13.0)$ & $8.0(4.0-15.0)$ & $7.0(3.0-13.0)^{\dagger}$ & 0.0074 \\
\hline Survivors at ICU discharge & $9.0(5.0-15.0)$ & $8.0(4.0-14.0)$ & $6.0(3.0-11.0)^{* \dagger}$ & 0.0002 \\
\hline
\end{tabular}

Abbreviations: $A R D S$ acute respiratory distress syndrome, $B M I$ body mass index, COPD chronic obstructive pulmonary disease, $F I O_{2}$ fraction of inspired oxygen, $P_{a} \mathrm{O}_{2}$ arterial oxygen partial pressure, $P_{a} C_{2}$ arterial carbon dioxide partial pressure, $P E E P$ positive end-expiratory pressure, $P I P$ peak inspiratory pressure, $q_{1}$ first quartile, $q_{3}$ third quartile, SOFA sepsis-related organ failure assessment, $S D$ standard deviation, $\mathrm{SpO}_{2}$ peripheral oxygen saturation

'Plateau pressure and driving pressure values are limited to patients in whom this value was reported and in whom either an assist control mode was used or in whom a mode permitting spontaneous ventilation was used and where the set and total respiratory rates were equal. Patients receiving HFOV or ECMO were also excluded

${ }^{\ddagger}$ Percentage was calculated on patients with $\mathrm{FIO}_{2}$ available during the second day and with $\mathrm{FIO}_{2} \geq 0.60$ at day 1

* $p$ value $<0.05$ (Bonferroni's correction), comparison with "Hypoxemia" group

${ }^{\dagger} p$ value $<0.05$ (Bonferroni's correction), comparison with "Normoxemia" group

Statistical Computing, http://www.R-project.org) and SAS software, version 9.4 (SAS Institute, Cary, NC, USA).

\section{Results}

Of 4499 patients that developed AHRF in the LUNG SAFE cohort, 2127 of these developed ARDS within 2 days of ICU admission, of whom 2052 remained in ICU for at least 2 days from ARDS onset. The study population consists of 2005 of these patients that did not receive ECMO (Fig. 1).

\section{Systemic oxygen tensions}

In the study population, 607 subjects (30\%) were hyperoxemic, while $6.5 \%$ of patients remained hypoxemic, on day 1 of ARDS (Fig. 2a, Table 1, eTable 1). Density distributions of arterial oxygen tension on days 1 and 2 of ARDS (Fig. 2b) reveal similar $\mathrm{PaO}_{2}$ profiles for days 1 and 2 . In the hyperoxemic population at day $1,59 \% \mathrm{had}$ a transient hyperoxemia, while in 250 (41\%) patients, the condition was sustained, with $\mathrm{PaO}_{2}>100 \mathrm{mmHg}$ on both the first and second day of ARDS (Fig. 1; eTable 2). All eTables are included in Additional file 1.

A multivariable analysis of factors independently associated with day 1 hyperoxemia identified higher $\mathrm{FIO}_{2}$ use, lower PEEP, lower respiratory rate, a lower sepsis- related organ failure assessment (SOFA) cardiovascular score, and comorbidities such as neoplasm and/or immunosuppression and heart failure (Table 2).

\section{Use of oxygen}

$\mathrm{FIO}_{2}$ use varied widely across the spectrum of $\mathrm{PaO}_{2}$ on day 1 of ARDS (Fig. 2c). In patients that received a $\mathrm{FIO}_{2}$ greater than 0.9 (459 patients), 11\% had systemic hypoxemia, while $38 \%$ had hyperoxemia (Fig. 2c). Median $\mathrm{PaO}_{2}$ was similar across deciles of $\mathrm{FIO}_{2}$ (Fig. 3a). On day 2 of ARDS, the proportions of patients receiving higher $\mathrm{FIO}_{2}$ decreased, although around one third of patients were hyperoxemic at each decile of $\mathrm{FIO}_{2}$ (Figs. 2d and 3b, c). In contrast, $40 \%(57 / 131)$ of patients with hypoxemia on day 1 received a $\mathrm{FIO}_{2}$ of 0.5 or less. Median $\mathrm{FIO}_{2}$ decreased between day 1 and day 2 in patients with hyperoxemia, normoxemia, and hypoxemia (Fig. 3b), although median $\mathrm{PaO}_{2}$ remained similar across deciles of $\mathrm{FIO}_{2}$ on day 2 (Fig. 3c).

Excess oxygen use was seen in 400 patients, comprising $66 \%$ of all patients with hyperoxemia, on day 1 of ARDS (Table 1). In 315 patients (79\%), excess oxygen use was transient, while in 85 (21\%) patients, excess oxygen use was also seen on day 2 of ARDS. In multivariable analysis, factors independently associated with excess oxygen use included lower $\mathrm{PaO}_{2} / \mathrm{FIO}_{2}$ ratio, 
Table 2 Factors associated with day 1 hyperoxemia $\left(\mathrm{PaO}_{2}>100 \mathrm{mmHg}\right)$ and with excess oxygen use $(\mathrm{FlO} 2 \geq 0.6$ in patients with $\mathrm{P}_{\mathrm{a}} \mathrm{O}_{2}>100 \mathrm{mmHg}$ ) in the study population

\begin{tabular}{|c|c|c|}
\hline Parameter & Odds ratio ( $95 \%$ confidence interval) & $p$ value \\
\hline \multicolumn{3}{|l|}{ Outcome-hyperoxemia at day 1 (model* on 1855 patients) } \\
\hline $\mathrm{FIO}_{2}$ (0.1 unit) & $1.168(1.115 ; 1.224)$ & $<.0001$ \\
\hline Bicarbonate $(\mathrm{mmol} / \mathrm{L})$ & $0.967(0.951 ; 0.984)$ & $<.0001$ \\
\hline Total respiratory rate (breath/min) & $0.971(0.956 ; 0.986)$ & 0.0002 \\
\hline PEEP $\left(\mathrm{cmH}_{2} \mathrm{O}\right)$ & $0.944(0.910 ; 0.979)$ & 0.0017 \\
\hline Active/hematologic neoplasm or immunosuppression (ref. no.) & $1.414(1.111 ; 1.801)$ & 0.0050 \\
\hline SOFA score - Cardiovascular & $0.925(0.870 ; 0.984)$ & 0.0139 \\
\hline Heart failure (ref. no.) & $1.482(1.080 ; 2.033)$ & 0.0148 \\
\hline \multicolumn{3}{|l|}{ Outcome-excess oxygen use at day 1 (model on 1694 patients) } \\
\hline $\mathrm{P}_{\mathrm{a}} \mathrm{O}_{2} / \mathrm{FIO}_{2}(\mathrm{mmHg})$ & $0.978(0.976 ; 0.980)$ & $<.0001$ \\
\hline $\operatorname{PEEP}\left(\mathrm{cmH}_{2} \mathrm{O}\right)$ & $1.144(1.091 ; 1.199)$ & $<.0001$ \\
\hline $\mathrm{PIP}\left(\mathrm{cmH}_{2} \mathrm{O}\right)$ & $1.029(1.014 ; 1.045)$ & 0.0002 \\
\hline Bicarbonate $(\mathrm{mmol} / \mathrm{L})$ & $0.971(0.954 ; 0.989)$ & 0.0013 \\
\hline Age (years) & $0.988(0.981 ; 0.996)$ & 0.0023 \\
\hline $\mathrm{BMI}\left(\mathrm{kg} / \mathrm{m}^{2}\right)$ & $0.980(0.965 ; 0.995)$ & 0.0111 \\
\hline Tidal volume (ml/kg IBW) & $1.081(1.017 ; 1.149)$ & 0.0122 \\
\hline
\end{tabular}

Abbreviations: $B M I$ body mass index, $\mathrm{FIO}_{2}$ fraction of inspired oxygen, $P E E P$ positive end-expiratory pressure, $P I P$ peak inspiratory pressure, SOFA sepsis-related organ failure, $\mathrm{P}_{a} \mathrm{O}_{2}$ arterial oxygen partial pressure, IBW ideal body weight

*Multivariable logistic model with presence of hyperoxemia $\left(\mathrm{PaO}_{2}>100 \mathrm{mmHg}\right)$ as dependent dichotomous variable and the predictors were identified by stepwise approach. One hundred and fifty patients were excluded due to missing values for the response or explanatory variables. List of possible predictors in stepwise approach: age, sex, body mass index, comorbidities (presence of heart failure, diabetes mellitus chronic renal failure, chronic obstructive pulmonary disease or home ventilation, active neoplasm of hematologic neoplasm or immunosuppression), ARDS risk factors (none, only non-pulmonary, only pulmonary, both types), bicarbonates concentration, management factors (presence of invasive mechanical ventilation, tidal volume, PEEP, PIP, total respiratory rate, minute ventilation), and $\mathrm{FIO}_{2}$ and SOFA components (CNS, cardiovascular, renal, liver, coagulation score)

${ }^{\circ}$ Multivariable logistic model with excess of oxygen use $\left(\mathrm{FIO}_{2} \geq 0.6\right.$ and $\left.\mathrm{PaO}_{2}>100 \mathrm{mmHg}\right)$ as dependent dichotomous variable and predictors identified by stepwise approach. Three hundred and eleven observations were deleted due to missing values for the response or explanatory variables

List of possible predictors in stepwise approach: age, sex, body mass index, comorbidities (presence of heart failure, diabetes mellitus chronic renal failure, chronic obstructive pulmonary disease or home ventilation, active neoplasm of hematologic neoplasm or immunosuppression), ARDS risk factors (none, only nonpulmonary, only pulmonary, both types), bicarbonates concentration, management factors (presence of invasive mechanical ventilation, tidal volume, PEEP, PIP, total respiratory rate, minute ventilation), and $\mathrm{PaO}_{2} / \mathrm{FIO}_{2}$ ratio and non-respiratory SOFA components (CNS, cardiovascular, renal, liver, coagulation score)

higher PEEP, higher tidal volume, and chronic renal failure (Table 2).

\section{Hyperoxemia, excess oxygen use, and outcome}

On day 1 , LOESS demonstrated the relationship between unadjusted mortality risk and $\mathrm{PaO}_{2}$ was relatively flat over the range of $\mathrm{PaO} 2$ (Fig. 4a). On day 2, the unadjusted risk of hospital mortality increased in patients with systemic hypoxemia (Fig. 4b). LOESS in non-hypoxemic patients demonstrated that unadjusted mortality risk increased with increasing $\mathrm{FIO}_{2}$ on both days 1 and 2 (Fig. 4c, d).

Multivariate analyses found no independent association between day 1 systemic oxygen tension or inspired oxygen concentration and outcome, in either the full study population or in the subset of patients with hyperoxemia (Table 3).

In a propensity-matched analysis $(n=448)$, no outcome differences were found in patients with sustained hyperoxemia compared to matched sustained normoxemia patients (Fig. 5a; eTable 3). Similarly, mortality in patients with hyperoxemia and excess oxygen use (42\%) was not different to that in patients with normoxemia $(39 \%, P=0.47)$ in a propensity-matched sample $(n=666)$ (Fig. 5b; eTable 4).

\section{Discussion}

Our findings demonstrate that hyperoxemia and excess $\mathrm{FIO}_{2}$ use was prevalent in patients with early ARDS in patients enrolled in the LUNG SAFE cohort. Hyperoxemia occurred in $30 \%$ of patients, while two thirds of these patients received excess oxygen therapy. While a similar proportion of patients was hyperoxemic on day 2 of ARDS, higher $\mathrm{FIO}_{2}$ use did decrease. Consequently, most day 2 hyperoxemia was seen in patients at lower $\mathrm{FIO}_{2}$, in whom gas exchange was improving. In the majority of patients, both hyperoxemia and excess oxygen use were transient, although sustained hyperoxemia occurred in $12 \%$ of patients. Higher $\mathrm{FIO}_{2}$ use was independently associated with the risk of hyperoxemia, illustrating the need for close attention to oxygen use to reduce this risk. We found no relationship between the degree and duration of hyperoxemia or of excessive 

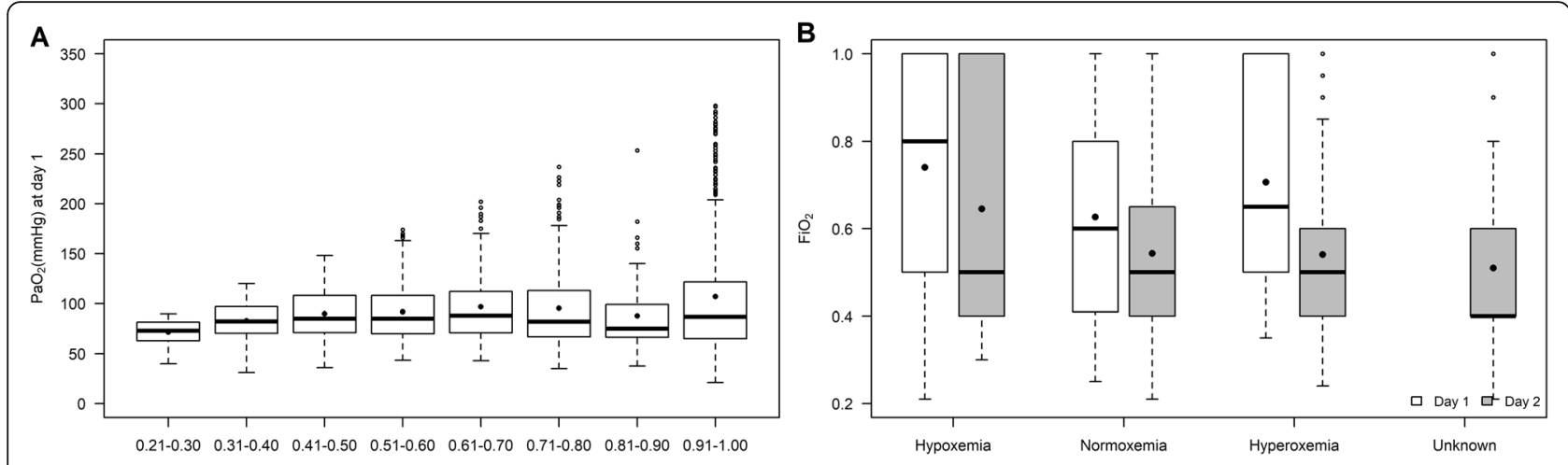

$$
\mathrm{FiO}_{2} \text { at day } 1
$$

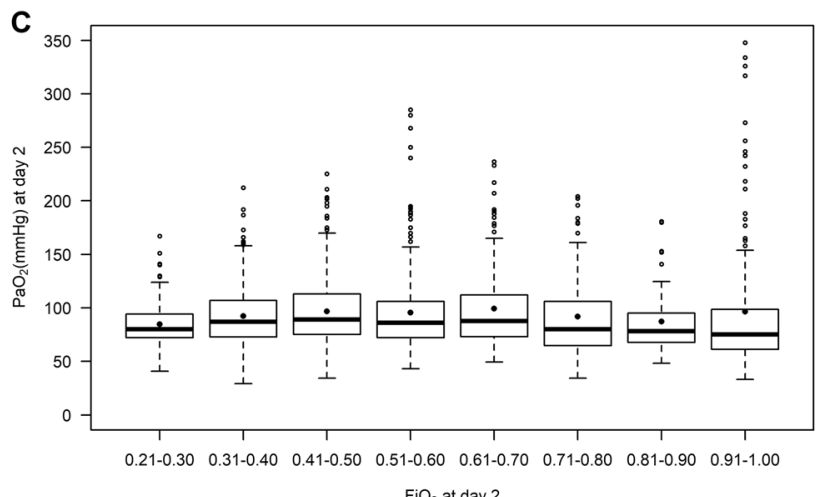

$\mathrm{FiO}_{2}$ at day 2

Fig. 3 Use of inspired oxygen in patients on days 1 and 2 of ARDS. a A box plot of $\mathrm{PaO}_{2}$ at each decile of FIO 2 uses on day 1 of ARDS. $\mathbf{b} \mathrm{A}$ box plot of $\mathrm{FIO}_{2}$ used on day 1 and 2 of ARDS in the study population classified by $\mathrm{PaO}_{2}$ on day 2 (hypoxemia, normoxemia, hyperoxemia, and unknown). c $\mathrm{A}$ box plot of $\mathrm{PaO}_{2}$ at each decile of $\mathrm{FIO}_{2}$ used on day 2 of ARDS

oxygen use, and outcome in early ARDS, in this patient cohort.

\section{Oxygen use in ARDS}

The optimal use of oxygen in patients with ARDS remains unclear. While guidelines recommend the use of supplemental oxygen during acute hypoxemia [38], specific therapeutic goals in terms of $\mathrm{PaO}_{2}$ or $\mathrm{SpO}_{2}$ are lacking. The ARDS Network targeted a $\mathrm{PaO}_{2}$ of $55-80$ mmHg in the ARMA trial of patients with ARDS [39]. The British Thoracic Society suggested a target $\mathrm{SpO}_{2}$ of 94-98\% in acutely ill patients who are not at risk of hypercapnic respiratory failure (only Grade D recommendation) [40, 41].

Tissue hypoxia directly causes cellular death, leading to organ failure and increased mortality in ICU patients. In contrast, high oxygen concentrations may be directly toxic to the lung via mechanisms that remain poorly characterized but may include alveolar-capillary "leak" and fibrogenesis [42, 43], arterial vasoconstriction $[18,19]$, and the production of reactive oxygen species with consequent proinflammatory and cytotoxic effects [20-22]. Consequently, clinicians are faced with the task of titrating the amount of oxygen delivered to avoid both hypoxemia and hyperoxemia. Prior studies show that clinicians appear to use higher $\mathrm{FIO}_{2}$ than is necessary in the critically ill [3]. While the reasons are unclear, potential explanations include concerns over the need to avoid tissue hypoxia, $[4,5]$ a desire to provide a "buffer" should a clinical deterioration occur, or because the consequences of hyperoxia are considered less severe than hypoxia.

\section{Hyperoxemia in ARDS}

In this study, hyperoxemia was seen on day 1 in a third of ARDS patients enrolled in the LUNG SAFE study. The fact that hyperoxemia was more prevalent than hypoxemia in patients immediately following the onset of ARDS, might seem surprising given that ARDS is a syndrome defined by impaired gas exchange but presumably reflects the effectiveness of ventilatory support and oxygen therapy. Of interest, hyperoxemia was associated with lower SOFA cardiovascular scores, suggesting that clinicians were not permitting hyperoxemia as a "buffer" in patients with shock. In this patient cohort, hyperoxemia was relatively transient in the majority of patients in early ARDS. 

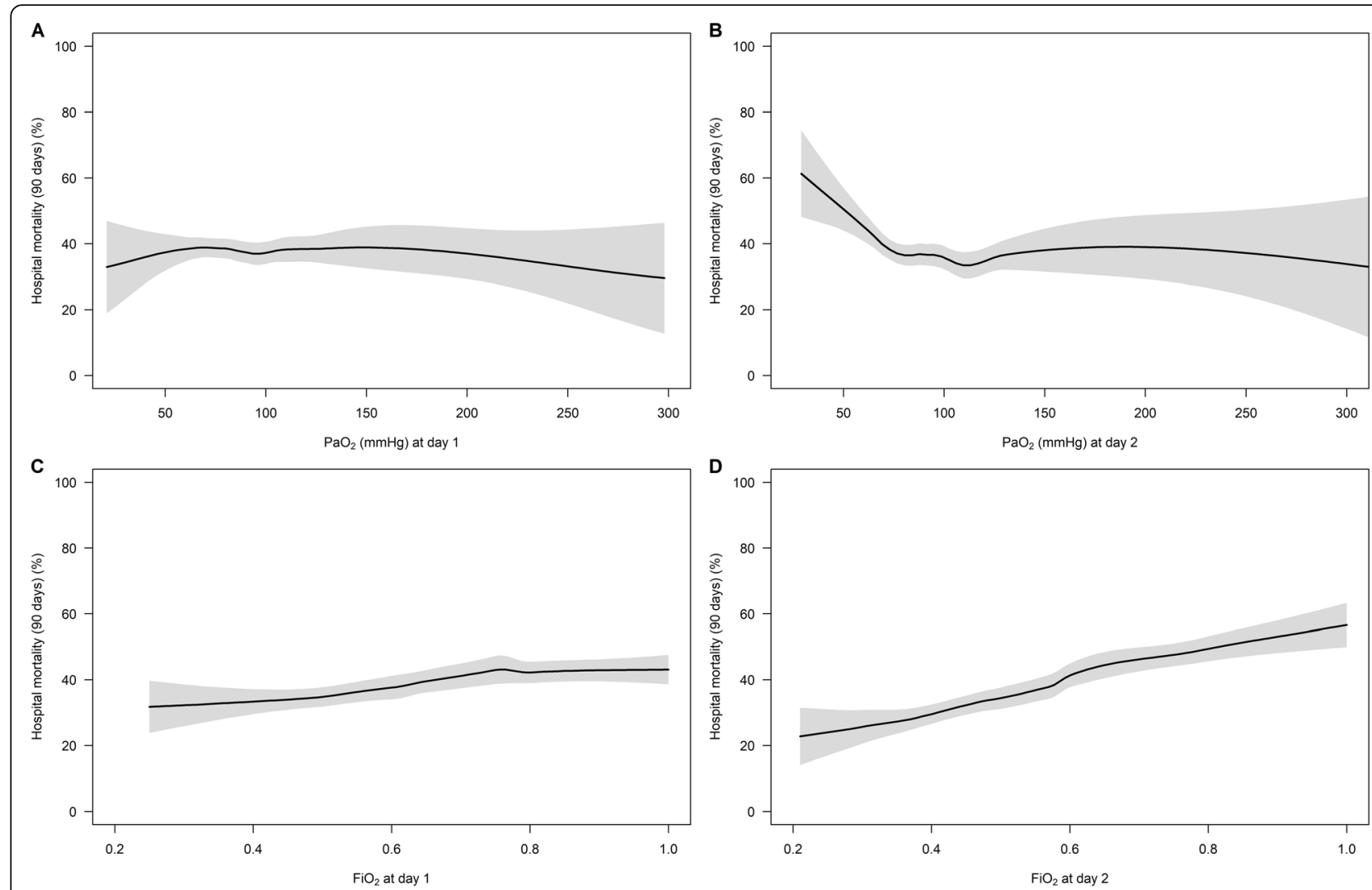

Fig. 4 Relationship between oxygen and outcome in patients with ARDS. a A locally estimated scatterplot smoothing (LOESS) of the relationship between $\mathrm{PaO}_{2}$ on day 1 of ARDS and mortality risk. $\mathbf{b} \mathrm{A}$ LOESS of the relationship between $\mathrm{PaO}_{2}$ use on day 2 of ARDS and mortality risk. $\mathbf{c} A$ LOESS of the relationship between $\mathrm{FIO}_{2}$ use on day 1 in non-hypoxemic patients with ARDS and mortality risk. $\mathbf{d}$ A LOESS of the relationship between $\mathrm{FIO}_{2}$ use on day 2 in non-hypoxemic patients with ARDS and mortality risk. Note: LOESS uses a bandwidth 2/3 and 1 degree of polynomial regression

A minority of patients had sustained hyperoxemia in this cohort. Interestingly, day 2 median $\mathrm{FIO}_{2}$ was the same in patients with sustained hyperoxemia and normoxemia, while $\mathrm{P} / \mathrm{F}$ ratio was substantially higher in the hyperoxemic patients. These findings suggest that sustained hyperoxemia in these patients is a function of rapidly improving gas exchange rather than excess oxygen use. Sustained hyperoxemia did not have a demonstrable impact on patient mortality. In the matched propensity score analysis, outcomes in patients with sustained hyperoxemia were comparable to that seen in normoxemic patients.

These findings contrast with prior findings regarding hyperoxemia in other critically ill cohorts. However, an important difference between these studies and the current study relates to the severity of hyperoxemia. De Jonge and colleagues reported an association between early hyperoxemia and outcome in patients with acute respiratory failure in the Netherlands [44]. However, this association was only seen in patients with relatively severe hyperoxemia $\left(\mathrm{PaO}_{2}>123 \mathrm{mmHg}\right.$; uncommon in our cohort) and only on day 1 of ICU admission, while there was no adverse association between hyperoxia over the entire ICU stay and patient outcome. The potential for harm from hyperoxia in the critically ill appears to be enhanced with greater severity and "dose" of hyperoxemia [45]. In fact, in critically ill patient groups where lung function was relatively preserved, such as patients post cardiac arrest, harm was mainly associated with systemic oxygen tensions over $300 \mathrm{mmHg}$ [13]. Greater degrees of hyperoxemia were likely in both the study by Girardis et al. [24] and in the HYPERS2S trial [23] of "induced" systemic hyperoxemia in patients with sepsis. Our study was focused solely on patients with ARDS, where due to their impaired gas exchange, they cannot attain this severity of systemic hyperoxia.

\section{Oxygen use in ARDS}

High inspired oxygen use was frequent in patients on day 1 of ARDS, with two thirds of patients with systemic hyperoxia receiving at least $60 \%$ oxygen in day 1 -which we termed "excess oxygen use" on the basis that these patients could safely have had their $\mathrm{FIO}_{2}$ reduced while maintaining normoxemia. Of importance, high $\mathrm{FIO}_{2}$ use 
Table 3 Factors associated with hospital mortality in study population $(n=2005)$ and in patients with hyperoxemia at day $1(n=607)$

\begin{tabular}{|c|c|c|}
\hline Factor & Odds ratio ( $95 \%$ confidence interval) & $p$ value \\
\hline \multicolumn{3}{|l|}{ Study population $(n=2005)$-model on 1360 patients } \\
\hline Age (year) & $1.022(1.015 ; 1.030)$ & $<.0001$ \\
\hline $\mathrm{BMI}\left(\mathrm{kg} / \mathrm{m}^{2}\right)$ & $0.978(0.962 ; 0.995)$ & 0.0098 \\
\hline SOFA score-cardiovascular & $1.182(1.096 ; 1.275)$ & $<.0001$ \\
\hline SOFA score-respiratory & $1.405(1.182 ; 1.669)$ & 0.0001 \\
\hline SOFA score-renal & $1.209(1.087 ; 1.344)$ & 0.0005 \\
\hline SOFA score-central nervous system & $1.147(1.061 ; 1.240)$ & 0.0006 \\
\hline Active/hematologic neoplasm or immunosuppression (ref. no.) & $2.248(1.697 ; 2.978)$ & $<.0001$ \\
\hline Chronic liver failure (ref. no.) & $4.315(2.184 ; 8.523)$ & $<.0001$ \\
\hline $\mathrm{PIP}\left(\mathrm{cmH}_{2} \mathrm{O}\right)$ & $1.030(1.013 ; 1.046)$ & 0.0003 \\
\hline Invasive mechanical ventilation (ref. no.) & $0.497(0.339 ; 0.729)$ & 0.0004 \\
\hline Bicarbonate $(\mathrm{mmol} / \mathrm{L})$ & $0.979(0.960 ; 0.997)$ & 0.0240 \\
\hline \multicolumn{3}{|l|}{ Patients with $\mathrm{P}_{\mathrm{a}} \mathrm{O}_{2}>100 \mathrm{mmHg}(n=607)$-model on 530 patients } \\
\hline Age (year) & $1.031(1.018 ; 1.044)$ & $<.0001$ \\
\hline SOFA score —renal & $1.362(1.152 ; 1.610)$ & 0.0003 \\
\hline SOFA score-cardiovascular & $1.205(1.073 ; 1.352)$ & 0.0016 \\
\hline Active/hematologic neoplasm or immunosuppression (ref. no) & $1.828(1.186 ; 2.819)$ & 0.0063 \\
\hline Chronic liver failure (ref. no.) & $4.091(1.256 ; 13.328)$ & 0.0194 \\
\hline Total respiratory rate (breath/min) & $1.043(1.015 ; 1.072)$ & 0.0027 \\
\hline Bicarbonate $(\mathrm{mmol} / \mathrm{L})$ & $0.958(0.924 ; 0.994)$ & 0.0210 \\
\hline
\end{tabular}

Abbreviations: BMI body mass index, PIP peak inspiratory pressure, SOFA sepsis-related organ failure assessment

was frequently transient, with a marked decrease in higher inspired oxygen concentration use on day 2 . Nevertheless, at each decile of $\mathrm{FIO}_{2}$, approximately one third of patients were hyperoxemic, suggesting the potential existed to further reduce oxygen use. Of interest, there was an association between excess oxygen use and the use of higher tidal volumes.

Our unadjusted analyses suggested an association between higher $\mathrm{FIO}_{2}$ and poorer outcome. However, in multivariate analyses, which accounted for lung injury severity, we found no independent association between high $\mathrm{FIO}_{2}$ use and patient outcome. Propensity-matched analyses in patients excess $\mathrm{FIO}_{2}$ confirmed no difference in mortality compared to normoxemic patients.

Our findings do not support prior concerns [24] raised regarding the use of higher $\mathrm{FIO}_{2}$ in patients with ARDS that are not hypoxemic. This finding also contrasts with the analysis of patients in the ARDS Network trials that found that the cumulative duration of "above target" oxygen exposure $\left(\mathrm{FIO}_{2}\right.$ above 0.5 in ARDS patients while $\mathrm{PaO}_{2}$ was $>80 \mathrm{mmHg}$ ) was associated with mortality [27]. While the reasons for the divergent findings are unclear, potential explanations include the fact that our analysis concentrated on early ARDS, the fact that high $\mathrm{FIO}_{2}$ use was transient in most patients in our cohort, and the fact that this analysis may have been better adjusted for the impact of lung injury severity.

\section{Limitations}

This study has several limitations. The non-linearity of $P / F$ ratio at different $\mathrm{FIO}_{2}$ [46] makes it difficult to predict the effect of $\mathrm{FIO}_{2}$ on $\mathrm{PaO}_{2} / \mathrm{FIO}_{2}$, especially when matching patients with mild ARDS. While we have adjusted our analyses to account for known measured confounders, the possibility remains that some of our findings may arise from unmeasured or residual confounding. Moreover, we cannot make causal inferences for any associations seen, given the observational nature of our study. Our dataset comprises daily arterial blood gas and $\mathrm{FIO}_{2}$ data, taken at a standardized time each morning. It is possible that these data do not properly reflect the spectrum of $\mathrm{FIO}_{2}$ use and $\mathrm{PaO}_{2}$ data over the course of that day. Given this, in the hyperoxemia analyses, we focused on patients that were hyperoxemic on both days 1 and 2 of ARDS. There are no single accepted definitions for hyperoxemia, hypoxemia, or excess oxygen use, so our definitions are of necessity arbitrary, and other definitions have been used in other analyses. This could partly explain any divergence in findings across these studies. Lastly, our assumption that 


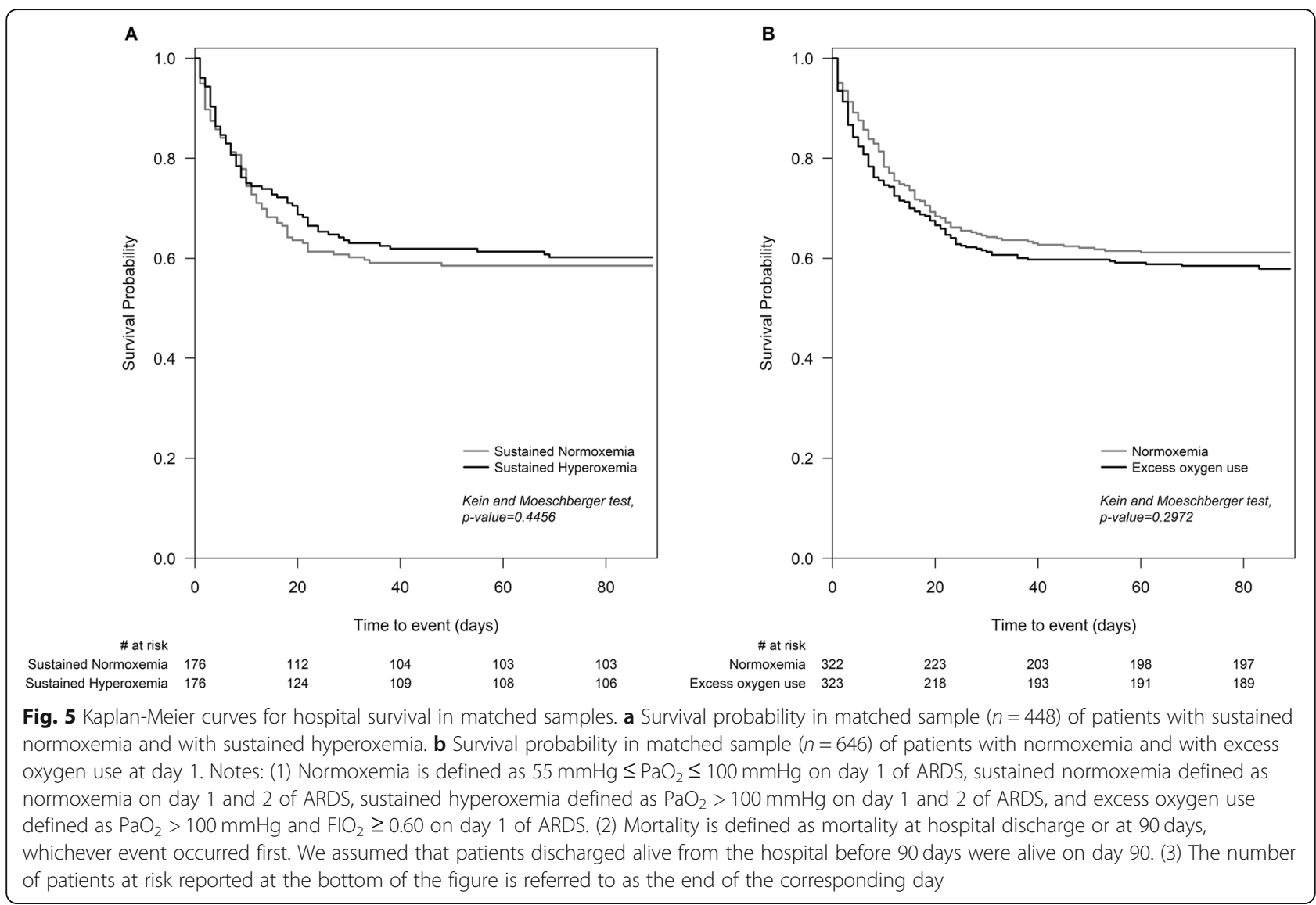

inpatients at day 90 survived to hospital discharge is a further limitation.

\section{Conclusions}

Our findings demonstrate that hyperoxemia and high fractional inspired oxygen use is prevalent in patients with early ARDS in patients enrolled in the LUNG SAFE cohort. Higher $\mathrm{FIO}_{2}$ use decreased from day 1 to day 2 of ARDS, with most day 2 hyperoxemia seen in patients at lower $\mathrm{FIO}_{2}$, in whom gas exchange was improving. Reassuringly, we found no relationship between hyperoxemia or excessive oxygen use and patient outcome in this cohort.

\section{Supplementary information}

Supplementary information accompanies this paper at https://doi.org/10. 1186/s13054-020-2826-6.

Additional file 1. Online Methodology and eTables. Expanded Methods and Materials. eTable 1: Comorbidities and risk factors in study population $(n=2005)$, stratified by arterial oxygenation on day 1 . eTable 2. Characteristics of patients with sustained normoxemia and sustained hyperoxemia. eTable 3: Characteristics at ARDS onset and clinical outcomes in matched sample $(n=354)$ of patients with sustained normoxemia and with sustained hyperoxemia. eTable 4 . Characteristics at ARDS onset and clinical outcomes in matched sample $(n=646)$ of patients with normoxemia and with excess oxygen use at day 1 .

\section{Abbreviations}

ARDS: Acute respiratory distress syndrome; ICUs: Intensive care units; LUNG SAFE: Large Observational Study to Understand the Global Impact of Severe Acute Respiratory Failure; ESICM: European Society of Intensive Care Medicine; $\mathrm{PaO}_{2}$ : Arterial oxygen tension; $\mathrm{FlO}_{2}$ : Fraction of inspired oxygen; MV: Invasive mechanical ventilation; ANOVA: Analysis of variance; LOESS: Locally estimated scatterplot smoothing; OR: Odds ratio; Cl: Confidence interval; SOFA: Sepsis-related organ failure assessment

\section{Acknowledgements}

We wish to acknowledge the help of Guy Francois of the European Society of Intensive Care Medicine, Brussels, Belgium, for his assistance with the study.

LUNG SAFE Steering Committee: Antonio Pesenti, John G. Laffey, Laurent Brochard, Andres Esteban, Luciano Gattinoni, Frank van Haren, Anders Larsson, Daniel F. McAuley, Marco Ranieri, Gordon Rubenfeld, B. Taylor Thompson, Hermann Wrigge, Arthur S. Slutsky.

LUNG SAFE National Coordinators: Argentina: Fernando Rios; Australia/New Zealand: Frank Van Haren; Belgium: Sottiaux T, Depuydt P; Bolivia: Fredy S Lora; Brazil: Luciano Cesar Azevedo; Canada: Eddy Fan; Chile: Guillermo Bugedo; China: Haibo Qiu; Colombia: Marcos Gonzalez; Costa Rica: Juan Silesky; Czech Republic: Vladimir Cerny; Denmark: Jonas Nielsen; Ecuador: Manuel Jibaja; France: Tài Pham; Germany: Hermann Wrigge; Greece: Dimitrios Matamis; Guatemala: Jorge Luis Ranero; India: Pravin Amin; Iran: S.M. Hashemian; Ireland: Kevin Clarkson; Italy: Giacomo Bellani; Japan: Kiyoyasu Kurahashi; Mexico: Asisclo Villagomez; Morocco: Amine Ali Zeggwagh; Netherlands: Leo M Heunks; Norway: Jon Henrik Laake; Philippines: Jose Emmanuel Palo; Portugal: Antero do Vale Fernandes; Romania: Dorel Sandesc; Saudi Arabia: Yaasen Arabi; Serbia: Vesna Bumbasierevic; Spain: Nicolas Nin, Jose A Lorente; Sweden: Anders Larsson; Switzerland: Lise Piquilloud; Tunisia: Fekri Abroug; UK: Daniel F McAuley, Lia McNamee; Uruquay: Javier Hurtado; USA: Ed Bajwa; Venezuela: Gabriel Démpaire LUNG SAFE Site Investigators (by Country): 
Albania: Uhc Mother Theresa (Tirana): Hektor Sula, Lordian Nunci; University Hospital Shefaet Ndroqi (Tirana): Alma Cani

Argentina: Clinica De Especialidades (Villa Maria): Alan Zazu; Hospital Dr Julio C. Perrando (Resistencia): Christian Dellera, Carolina S Insaurralde; Sanatorio Las Lomas (San Isidro, Buenos Aires): Risso V Alejandro; Sanatorio De La Trinidad San Isidro (San Isidro): Julio Daldin, Mauricio Vinzio; Hospital Español De Mendoza (Godoy Cruz - Mendoza): Ruben O Fernandez; Hospital Del Centenario (Rosario): Luis P Cardonnet, Lisandro R Bettini; San Antonio (Gualeguay (Entre Rios)): Mariano Carboni Bisso, Emilio M Osman; Cemic (Buenos Aires): Mariano G Setten, Pablo Lovazzano; Hospital Universitrario Austral (Pilar): Javier Alvarez, Veronica Villar; Hospital Por + Salud (Pami) Dr. Cesar Milstein (Buenos Aires): Norberto C Pozo, Nicolas Grubissich; Sanatorio Anchorena (Buenos Aires): Gustavo A Plotnikow, Daniela N Vasquez; Sanatorio De La Trinidad Mitre (Buenos Aires): Santiago llutovich, Norberto Tiribelli; Hospital Luis Lagomaggiore (Mendoza): Ariel Chena, Carlos A Pellegrini; H.I.G.A San Martín (La Plata): María G Saenz, Elisa Estenssoro; Hospital Misericordia (Cordoba): Matias Brizuela, Hernan Gianinetto; Sanatorio Juncal (Temperley): Pablo E Gomez, Valeria I Cerrato; Hospital D. F. Santojanni (Buenos Aires): Marco G Bezzi, Silvina A Borello; Hospital Alejandro Posadas (Buenos Aires): Flavia A Loiacono, Adriana M Fernandez

Australia: St. Vincent's Hospital, Sydney (Darlinghurst): Serena Knowles, Claire Reynolds; St George Public Hospital (Kogarah): Deborah M Inskip, Jennene J Miller; Westmead Hospital (Westmead): Jing Kong, Christina Whitehead; Flinders Medical Centre (Bedford Park, South Australia): Shailesh Bihari; John Hunter Hospital (Newcastle): Aylin Seven, Amanda Krstevski; Canberra Hospital (Garran): Helen J Rodgers, Rebecca T Millar; Calvary Mater Newcastle (Waratah): Toni E Mckenna, Irene M Bailey; Cabrini Hospital (Melbourne): Gabrielle C Hanlon; Liverpool Hospital (Liverpool): Anders Aneman, Joan M Lynch; Coffs Harbour Health Campus (Coffs Harbour): Raman Azad, John Neal; Sir Charles Gairdner Hospital (Nedlands): Paul W Woods, Brigit L Roberts; Concord Hospital (Concord): Mark R Kol, Helen S Wong Austria: General Hospital Of Vienna/Medical University Of Vienna (Vienna): Katharina C Riss, Thomas Staudinger

Belgium: Cliniques universitaires St Luc, UCL (Brussels): Xavier Wittebole, Caroline Berghe; CHU Dinant-Godinne (Yvoir): Pierre A Bulpa, Alain M Dive; AZ Sint Augustinus Veurne (Veurne): Rik Verstraete, Herve Lebbinck; Ghent University Hospital (Ghent): Pieter Depuydt, Joris Vermassen; University Hospitals Leuven (Leuven): Philippe, Meersseman, Helga Ceunen

Brazil: Hospital Renascentista (Pouso Alegre): Jonas I Rosa, Daniel O Beraldo; Vitoria Apart Hospital (Serra): Claudio Piras, Adenilton M Rampinelli; Hospital Das Clinicas (São Paulo): Antonio P Nassar Jr; Hospital Geral Do Grajaù (São Paulo): Sergio Mataloun, Marcelo Moock; Evangelical Hospital (Cachoeiro De Itapemirim/Espírito Santo): Marlus M Thompson, Claudio H Gonçalves; Hospital Moinhos De Vento (Porto Alegre): Ana Carolina P Antônio, Aline Ascoli; Hospital Alvorada Taguatinga (Taguatinga): Rodrigo S Biondi, Danielle C Fontenele; Complexo Hospitalar Mngabeira Tarcisio Burity (Joao Pessoa): Danielle Nobrega, Vanessa M Sales

Brunei Darussalam: Raja Isteri Pengiran Anak Saleha (Ripas) Hospital (Bandar Seri Begawan): Dr. Suresh Shindhe, Dr. Dk Maizatul Aiman B Pg Hj Ismail Canada: Medical-Surgical ICU of St Michael's Hospital (Toronto): John Laffey, Francois Beloncle; St. Josephs Health Centre (Toronto): Kyle G Davies, Rob Cirone; Sunnybrook Health Sciences Center (Toronto): Venika Manoharan, Mehvish Ismail; Toronto Western Hospital (Toronto): Ewan C Goligher, Mandeep Jassal; Medical Surgical ICU of the Toronto General Hospital (Toronto): Erin Nishikawa, Areej Javeed; Cardiovascular ICU of St Michael's Hospital (Toronto): Gerard Curley, Nuttapol Rittayamai; Cardiovascular ICU of the Toronto General Hospital (Toronto): Matteo Parotto, Niall D Ferguson; Mount Sinai Hospital (Toronto): Sangeeta Mehta, Jenny Knoll; Trauma-Neuro ICU of St Michael's Hospital (Toronto): Antoine Pronovost, Sergio Canestrini Chile: Hospital Clínico Pontificia Universidad Católica De Chile (Santiago): Alejandro R Bruhn, Patricio H Garcia; Hospital Militar De Santiago (Santiago): Felipe A Aliaga, Pamela A Farías; Clinica Davila (Santiago): Jacob S Yumha; Hospital Guillermo Grant Benavente (Concepcion): Claudia A Ortiz, Javier E Salas; Clinica Las Lilas (Santiago): Alejandro A Saez, Luis D Vega; Hospital Naval Almirante Nef (Viña Del Mar): Eduardo F Labarca, Felipe T Martinez; Hospital Luis Tisné Brousse (Penanolen): Nicolás G Carreño, Pilar Lora China: The Second Affiliated Hospital Of Harbin Medical University (Harbin): Haitao Liu; Nanjing Zhong-Da Hospital, Southeast University (Nanjing): Haibo Qiu, Ling Liu; The First Affiliated Hospital Of Anhui Medical University (Hefei): Rui Tang, Xiaoming Luo; Peking University People's Hospital (Beijing): Youzhong An, Huiying Zhao; Fourth Affiliated Hospital Of Harbin Medical
University (Harbin): Yan Gao, Zhe Zhai; Nanjing Jiangbei Peoples Hospital Affiliated To Medical School Of Southeast University (Nanjing): Zheng L Ye, Wei Wang; The First Affiliated Hospital Of Dalian Medical University (Dalian): Wenwen Li, Qingdong Li; Subei Peoples Hospital Of Jiangsu Province (Yanghzou): Ruiqiang Zheng; Jinling Hospital (Nanjing): Wenkui Yu, Juanhong Shen; Urumqi General Hospital (Urumqi): Xinyu Li; Intensive Care Unit, First Affiliated Hospital Of Wanna Medical College, Yijishan Hospital, (Wuhu): Tao Yu, Weihua Lu; Sichuan Provincial Peoples Hospital (Chengdu): Ya Q Wu, Xiao B Huang; Hainan Province Peoples Hospital (Haikou): Zhenyang He; Peoples Hospital Of Jiangxi Province (Nanchang): Yuanhua Lu; Qilu Hospital Of Shandong University (Jinan): Hui Han, Fan Zhang; Zhejiang Provincial Peoples Hospital (Hangzhou): Renhua Sun; The First Affiliated Hospital Of Bengbu Medical College (Bengbu, Anhui): Hua X Wang, Shu H Qin; Nanjing Municipal Government Hospital (Nanjing): Bao H Zhu, Jun Zhao; The First Hospital Of Lanzhou University (Lanzhou): Jian Liu, Bin Li; The First Affiliated Hospital Of Chongqing University Of Medical Science (Chongqing): Jing L Liu, Fa C Zhou; Xuzhou Central Hospital, Jiangsu Province, China (Xuzhou): Qiong J Li, Xing Y Zhang; The First Peoples Hospital Of Foshan (Foshan): Zhou Li-Xin, Qiang Xin-Hua; The First Affiliated Hospital Of Guangxi Medical University (Nanning): Liangyan Jiang; Renji Hospital, Shanghai Jiao Tong University School Of Medicine (Shanghai): Yuan N Gao, Xian Y Zhao; First Hospital Of Shanxi Medical University (Taiyuan): Yuan Y Li, Xiao L Li; Shandong Provincial Hospital (Jinan): Chunting Wang, Qingchun Yao; Fujian Provincial Hospital (Fuzhou): Rongguo Yu, Kai Chen; Henan Provincial People's Hospital (Zhengzhou): Huanzhang Shao, Bingyu Qin; The Second Affiliated Hospital Of Kunming Medical University (Kunming City): Qing Q Huang, Wei H Zhu; Xiangya Hospital, Central South University (Changsha): Ai Y Hang, Ma X Hua; The First Affiliated Hospital Of Guangzhou Medical University (Guangzhou): Yimin Li, Yonghao Xu; Peoples Hospital of Hebei Province (Shijiazhuang): Yu D Di, Long L Ling; Guangdong General Hospital (Guangzhou): Tie H Qin, Shou H Wang; Beijing Tongren Hospital (Beijing): Junping Qin; Jiangsu Province Hospital (Nanjing): Yi Han, Suming Zhou

Colombia: Fundación Valle Del Lili (Cali): Monica P Vargas

Costa Rica: Hospital San Juan De Dios (San José): Juan I Silesky Jimenez, Manuel A González Rojas; Hospital San Juan De Dios (San José): Jaime E Solis-Quesada, Christian M Ramirez-Alfaro

Czech Republic: University Hospital Of Ostrava (Ostrava): Jan Máca, Peter Sklienka

Denmark: Aarhus Universitetshospital (Aarhus N): Jakob Gjedsted, Aage Christiansen; Rigshopitalet: Jonas Nielsen

Ecuador: Hospital Militar (Quito): Boris G Villamagua, Miguel Llano

France: Clinique du Millenaire (Montpellier): Philippe Burtin, Gautier Buzancais: Centre Hospitalier (Roanne): Pascal Beuret, Nicolas Pelletier; CHU d'Angers (Angers): Satar Mortaza, Alain Mercat; Hôpital Marc Jacquet (Melun): Jonathan Chelly, Sébastien Jochmans; CHU Caen (Caen): Nicolas Terzi, Cédric Daubin; Henri Mondor Hospital (Créteil): Guillaume Carteaux, Nicolas de Prost; Cochin Hospital (Paris): Jean-Daniel Chiche, Fabrice Daviaud; Hôpital Tenon (Paris): Tai Pham, Muriel Fartoukh; CH Mulhouse-Emile Muller (Mulhouse): Guillaume Barberet, Jerome Biehler; Archet 1 University Hospital (Nice): Jean Dellamonica, Denis Doyen; Hopital Sainte Musse (Toulon): Jean-Michel Arnal, Anais Briquet; Hopital Nord - Réanimation des Détresses Respiratoires et Infections Sévères (Marseille): Sami Hraiech, Laurent Papazian; HEGP (Paris):Arnaud Follin; Louis Mourier Hospital (Colombes): Damien Roux, Jonathan Messika; Centre Hospitalier de Dax (Dax): Evangelos Kalaitzis; Réanimation Médicale, GH Pitié-Salpêtrière (Paris): Laurence Dangers, Alain Combes; Ap-Hp Ambroise Paré (Boulogne-Billancourt): Siu-Ming Au; University Hospital Rouen (Rouen): Gaetan Béduneau, Dorothée Carpentier; CHU Amiens (Amiens - Salouel): Elie H Zogheib, Herve Dupont; Centre Hospitalier Intercommunal Robert Ballanger (Aulnay Sous Bois): Sylvie Ricome, Francesco L Santoli; Centre Hospitalier René Dubos (Pontoise): Sebastien L Besset; CHI Portes de I'Oise (Beaumont Sur Oise): Philippe Michel, Bruno Gelée; Archet 2 University Hospital (Nice): Pierre-Eric Danin, Bernard Goubaux; Centre Hospitalier Pierre Oudot (Bourgoin Jallieu): Philippe J Crova, Nga T Phan; CH Dunkerque (Dunkerque): Frantz Berkelmans; Centre Hospitalier de Belfort Montbéliard (Belfort): Julio C Badie, Romain Tapponnier; Centre Hospitalier Emile Muller (Mulhouse): Josette Gally, Samy Khebbeb; Hôpital de Hautepierre-Hôpitaux Universitaires de Strasbourg (Strasbourg): JeanEtienne Herbrecht, Francis Schneider; Centre Hospitalier de Dieppe (Dieppe): Pierre-Louis M Declercq, Jean-Philippe Rigaud; Bicetre (Le Kremin-Bicetre): Jacques Duranteau, Anatole Harrois; CHU Gabriel Montpied (Clermont-Ferrand): Russell Chabanne, Julien Marin; CHU Estaing (Clermont-Ferrand): Charlene Bigot, Sandrine Thibault; CHI Eure-Seine Evreux (Evreux): Mohammed Ghazi, Messabi Boukhazna; 
Centre Hospitalier d Châlons en Champagne (Châlons en Champagne): Salem Ould Zein; CH Beauvais (Beauvais): Jack R Richecoeur, Daniele M Combaux; Centre Hospitalier Le Mans (Le Mans): Fabien Grelon, Charlene Le Moal; Hôpital Fleyriat (Bourg en Bresse): Elise P Sauvadet, Adrien Robine; Hôpital Saint Louis (Paris): Virginie Lemiale, Danielle Reuter; Service de Pneumologie Pitié-Salpétrière (Paris): Martin Dres, Alexandre Demoule; Centre Hospitalier Gonesse (Gonesse): Dany Goldgran-Toledano; Hôpital Croix Rousse (Lyon): Loredana Baboi, Claude Guérin Germany: St. Nikolaus-Stiftshospital (Andernach): Ralph Lohner; Fachkrankenhaus Coswig Gmbh (Coswig):Jens Kraßler, Susanne Schäfer; University Hospital Frankfurt (Frankfurt am Main): Kai D Zacharowski, Patrick Meybohm; Department of Anaesthesia \& Intensive Care Medicine, University Hospital of Leipzig (Leipzig): Andreas W Reske, Philipp Simon; Asklepios Klinik Langen (Langen): Hans-Bernd F Hopf, Michael Schuetz; Städtisches Krankenhaus Heinsberg (Heinsberg): Thomas Baltus

Greece: Hippokrateion General Hospital Of Athens (Athens): Metaxia N Papanikolaou, Theonymfi G Papavasilopoulou; Gh Ahepa (Thessaloniki): Giannis A Zacharas, Vasilis Ourailogloy; Hippokration General Hospital of Thessaloniki (Thessaloniki): Eleni K Mouloudi, Eleni V Massa; Hospital General of Kavala (Kavala): Eva O Nagy, Electra E Stamou; Papageorgiou General Hospital (Thessaloniki): Ellada V Kiourtzieva, Marina A Oikonomou Guatemala: Hospital General De Enfermedades, Instituto Guatemalteco De Seguridad Social (Ciudad De Guatemala): Luis E Avila; Centro Médico Militar (Guatemala): Cesar A Cortez, Johanna E Citalán India: Deenanath Mangeshkar Hospital And Research Center (Pune): Sameer A Jog, Safal D Sable; Care Institute Of Medical Sciences (CIMS) Hospital (Ahmedabad): Bhagyesh Shah; Sanjay Gandhi Postgraduate Institute Of Medical Sciences (SGPGIMS) (Lucknow): Mohan Gurjar, Arvind K Baronia; Rajasthan Hospital (Ahmedabad): Mohammedfaruk Memon; National Institute Of Mental Health And Neuro Sciences (NIMHANS) (Bangalore): Radhakrishnan Muthuchellappan, Venkatapura J Ramesh; Anaesthesiology Unit of the Kasturba Medical College \& Dept of Respiratory Therapy, SHOAS, Manipal University (Manipal): Anitha Shenoy, Ramesh Unnikrishnan; Sanjeevan Hospital (Pune): Subhal B Dixit, Rachana V Rhayakar; Apollo Hospitals (Chennai): Nagarajan Ramakrishnan, Vallish K Bhardwaj; Medicine Unit of the Kasturba Medical College \& Dept of Respiratory Therapy, SHOAS, Manipal University (Manipal): Heera L Mahto, Sudha V Sagar; G Kuppuswamy Naidu Memorial Hospital (Coimbatore): Vijayanand Palaniswamy, Deeban Ganesan Iran: NRITLD/Masih Daneshvari (Tehran): Seyed Mohammadreza Hashemian, Hamidreza Jamaati; Milad Hospital (Tehran): Farshad Heidari Ireland: St Vincent's University Hospital (Dublin): Edel A Meaney, Alistair Nichol; Mercy University Hospital (Cork): Karl M Knapman, Donall O'Croinin; Cork University Hospital (Cork): Eimhin S Dunne, Dorothy M Breen; Galway University Hospital (Galway): Kevin P Clarkson, Rola F Jaafar; Beaumont Hospital (Dublin): Rory Dwyer, Fahd Amir; Mater Misericordiae University Hospital (Dublin): Olaitan O Ajetunmobi, Aogan C O'Muircheartaigh; Tallaght Hospital (Dublin): Colin S Black, Nuala Treanor; Saint James's Hospital (Dublin): Daniel V Collins, Wahid Altaf Italy: Santa Maria delle Croci Hospital (Ravenna): Gianluca Zani, Maurizio Fusari; Arcispedale Sant'Anna Ferrara. (Ferrara): Savino Spadaro, Carlo A Volta; Ospedale Profili (Fabriano) (An): Romano Graziani, Barbara Brunettini; Umberto I Nocera Inferiore (Nocera Inferiore Salerno): Salvatore Palmese; Azienda Ospedaliera San Paolo - Polo Universitario- Università degli Studi di Milano (Milan): Paolo Formenti, Michele Umbrello; Sant'Anna (San Fermo Della Battaglia (Co)): Andrea Lombardo; Spedali Civili Brescia (Brescia): Elisabetta Pecci, Marco Botteri; Fondazione Irccs Ca Granda, Ospedale Maggiore Policlinico (Milan): Monica Savioli, Alessandro Protti; University Campus Bio-Medico of Rome (Rome): Alessia Mattei, Lorenzo Schiavoni: Azienda Ospedaliera "Mellino Mellini" (Chiari (Bs)): Andrea Tinnirello, Manuel Todeschini; Policlinico P. Giaccone, University of Palermo (Palermo): Antonino Giarratano, Andrea Cortegiani; Niguarda Cà Granda Hospital (Milan): Sara Sher, Anna Rossi; A.Gemelli University Hospital (Rome): Massimo M Antonelli, Luca M Montini; Ospedale "Sandro Pertini" (Rome): Paolo Casalena, Sergio Scafetti; ISMeTT IRCCS UPMC (Palermo): Giovanna Panarello, Giovanna Occhipinti; Ospedale San Gerardo (Monza): Nicolò Patroniti, Matteo Pozzi; Santa Maria Della Scaletta (Imola): Roberto R Biscione, Michela M Poli; Humanitas Research Hospital (Rozzano): Ferdinando Raimondi, Daniela Albiero; Ospedale Desio - Ao Desio-Vimercate (Desio): Giulia Crapelli, Eduardo Beck; Pinetagrande Private Hospital (Castelvolturno): Vincenzo Pota, Vincenzo Schiavone; Irccs San Martino Ist (Genova): Alexandre Molin, Fabio Tarantino; Ospedale San Raffaele (Milano): Giacomo Monti, Elena Frati; Ospedali Riuniti Di Foggia (Foggia): Lucia Mirabella, Gilda Cinnella; Azienda Ospedaliera Luigi
Sacco - Polo Universitario (Milano): Tommaso Fossali, Riccardo Colombo; A.O.U. Città della Salute e della Scienza di Torino (Turin): Pierpaolo Terragni Ilaria Pattarino; Università degli Studi di Pavia-Fondazione IRCCS Policlinico San Matteo (Pavia): Francesco Mojoli, Antonio Braschi; Ao Ospedale Civile Legnano (Legnano): Erika E Borotto; Arnas Ospedale Civico Di Cristina Benfratelli (Palermo): Andrea N Cracchiolo, Daniela M Palma; Azienda Ospedaliera Della Provincia Di Lecco - Ospedale "A. Manzoni" (Lecco): Francesco Raponi, Giuseppe Foti; A.O. Provincia Di Lecco - Ospedale Alessandro Manzoni (Lecco): Ettore R Vascotto, Andrea Coppadoro; Cliniche Universitarie Sassari (Sassari): Luca Brazzi, Leda Floris; IRCCS Policlinico San Matteo (Pavia): Giorgio A lotti, Aaron Venti Japan: Yokohama City University Hospital (Yokohama): Osamu Yamaguchi, Shunsuke Takagi; Toyooka Hospital (Toyooka City, Hyogo Prefecture): Hiroki N Maeyama; Chiba University Hospital (Chiba City): Eizo Watanabe, Yoshihiro Yamaji; Okayma University Hospital (Okayama): Kazuyoshi Shimizu, Kyoko Shiozaki; Japanese Foundation for Cancer Research, Cancer Institute Hospital, Department Of Emergency Medicine And Critical Care (Tokyo): Satoru Futami; Ibaraki Prefectural Central Hospital (Kasama): Sekine Ryosuke; Tohoku University Hospital (Sendai-Shi): Koji Saito, Yoshinobu Kameyama; Tokyo Medical University Hachioji Medical Center (Hachioji, Tokyo): Keiko Ueno; Tokushima University Hospital (Tokushima): Masayo . Izawa, Nao Okuda; Maebashi Red Cross Hospital (Gunma Maebashi): Hiroyuki Suzuki, Tomofumi Harasawa; Urasoe General Hospital (Urasoe): Michitaka Nasu, Tadaaki Takada; Ohta General Hospital Foundation Ohta Nishinouchi Hospital (Fukushima): Fumihito Ito; Jichi Medical University Hospital (Shimotsuke): Shin - Nunomiya, Kansuke - Koyama; Mito Kyodo General Hospital, Tsukuba University Hospital Mito Medical Center (Mito): Toshikazu Abe; Sendai City Hospital (Sendai): Kohkichi Andoh, Kohei Kusumoto; Ja Hiroshima General Hospital (Hatsukaichi City, Hiroshima): Akira Hirata, Akihiro Takaba; Yokohama Rosai Hospital (Yokohama): Hiroyasu Kimura; Nagasaki University Hospital (Nagasaki): Shuhei Matsumoto, Ushio Higashijima; Niigata University Medical \& Dental Hospital (Niigata): Hiroyuki Honda, Nobumasa Aoki; Mie University Hospital (Tsu, Mie): Hiroshi Imai; Yamaguchi University Hospital (Ube, Yamaguchi): Yasuaki Ogino, Ichiko Mizuguchi; Saiseikai Kumamoto Hospital (Kumamoto City): Kazuya Ichikado; Shinshu University School Of Medecine (Matsumoto City): Kenichi Nitta, Katsunori Mochizuki; Kuki General Hospital (Kuki): Tomoaki Hashida; Kyoto Medical Center (Kyoto): Hiroyuki Tanaka; Fujita Health University (Toyoake): Tomoyuki Nakamura, Daisuke Niimi; Rakwakai Marutamachi Hospital (Kyoto): Takeshi Ueda; Osaka University Hospital (Suita City, Osaka Prefecture): Yozo Kashiwa, Akinori Uchiyama

Latvia: Paul Stradins Clinical University Hospital (Riga): Olegs Sabelnikovs, Peteris Oss Lebanon: Kortbawi Hospital (Jounieh): Youssef Haddad Malaysia: Hospital Kapit (Kapit): Kong Y Liew Mexico: Instituto Nacional De Cancerología, México (Mexico City): Silvio A Ñamendys-Silva, Yves D Jarquin-Badiola; Hospital De Especialidades "Antonio Fraga Mouret" Centro Medico Nacional La Raza IMSS (Mexico City): Luis A Sanchez-Hurtado, Saira S Gomez-Flores; Hospital Regional $1^{\circ}$ De Octubre (Mexico City): Maria C Marin, Asisclo J Villagomez; Hospital General Dr. Manuel Gea Gonzalez (Mexico City): Jordana S Lemus, Jonathan M Fierro; Hospital General De Zona No. 1 Instituto Mexicano Del Seguro Social Tepic Nayarit (Tepic): Mavy Ramirez Cervantes, Francisco Javier Flores Mejia; Centro Medico Dalinde (Mexico D.F.): Dulce Dector, Dulce M Dector; Opd Hospital Civil De Guadalajara Hospital Juan I Menchaca (Guadalajara): Daniel R Gonzalez, Claudia R Estrella; Hospital Regional De Ciudad Madero Pemex (Ciudad Madero): Jorge R Sanchez-Medina, Alvaro Ramirez-Gutierrez; Centro Médico ABC (Mexico D.F.): Fernando G George, Janet S Aguirre; Hospital Juarez De Mexico (Mexico City): Juan A Buensuseso, Manuel Poblano Morocco: Mohammed V University, University Teaching Ibn Sina Hospital (Rabat): Tarek Dendane, Amine Ali Zeggwagh; Hopital Militaire D'Instruction Mohammed V (Rabat): Hicham Balkhi; Errazi (Marrakech): Mina Elkhayari, Nacer Samkaoui; University Teaching Hospital Ibn Rushd (Casablanca): Hanane Ezzouine, Abdellatif Benslama; Hôpital des Spécialités de Rabat (HSR) (Rabat): Mourad Amor, Wajdi Maazouzi Netherlands: Tjongerschans (Heerenveen): Nedim Cimic, Oliver Beck; Cwz (Nijmegen): Monique M Bruns, Jeroen A Schouten; Rijnstate Hospital (Arnhem): Myra - Rinia, Monique Raaijmakers; Radboud Umc (Nijmegen): Leo M Heunks, Hellen M Van Wezel; Maastricht University Medical Centre (Maastricht): Serge J Heines, Ulrich Strauch; Catharinaziekenhuis (Eindhoven): Marc P Buise; Academic Medical Center (Amsterdam): Fabienne D Simonis, Marcus J Schultz 
New Zealand: Tauranga Hospital (Tauranga): Jennifer C Goodson, Troy S Browne; Wellington Hospital (Wellington): Leanlove Navarra, Anna Hunt; Dunedin Hospital (Dunedin): Robyn A Hutchison, Mathew B Bailey; Auckland City Hospital (Auckland): Lynette Newby, Colin Mcarthur; Whangarei Base Hospital (Whangarei): Michael Kalkoff, Alex Mcleod; North Shore Hospital (Auckland): Jonathan Casement, Danielle J Hacking

Norway: Ålesund Hospital (Ålesund): Finn H Andersen, Merete S Dolva; Oslo University Hospital - Rikshospitalet Medical Centre (Oslo): Jon H Laake, Andreas Barratt-Due; Stavanger University Hospital (Stavanger): Kim Andre L Noremark, Eldar Søreide; Haukeland University Hospital (Bergen): Brit A Sjøbø, Anne B Guttormsen

Peru: Hospital Nacional Edgardo Rebagliati Martins (Lima): Hector H Leon Yoshido; Clínica Ricardo Palma (Lima): Ronald Zumaran Aguilar, Fredy A Montes Oscanoa

Philippines: The Medical City (Pasig): Alain U Alisasis, Joanne B Robles; Chong Hua Hospital (Cebu): Rossini Abbie B Pasanting-Lim, Beatriz C Tan Poland: Warsaw University Hospital (Warsaw): Pawel Andruszkiewicz, Karina Jakubowska

Portugal: Centro Hospitalar Da Cova Da Beira (Covilhã): Cristina M Coxo; Hospital Santa Maria, Chln (Lisboa): António M Alvarez, Bruno S Oliveira; Centro Hospitalar Trás-Os-Montes E Alto Douro - Hospital De S.Pedro-Vila Real (Vila Real): Gustavo M Montanha, Nelson C Barros; Hospital Beatriz Ângelo (Loures): Carlos S Pereira, António M Messias; Hospital De Santa Maria (Lisboa): Jorge M Monteiro; Centro Hospitalar Médio Tejo - Hospital De Abrantes (Abrantes): Ana M Araujo, Nuno T Catorze; Instituto Português De Oncologia De Lisboa (Lisboa): Susan M Marum, Maria J Bouw; Hospital Garcia De Orta (Almada): Rui M Gomes, Vania A Brito; Centro Hospitalar Do Algarve (Faro): Silvia Castro, Joana M Estilita; Hpp Hospital De Cascais (Alcabideche): Filipa M Barros; Hospital Prof. Doutor Fernando Fonseca Epe (Amadora): Isabel M Serra, Aurelia M Martinho

Romania: Fundeni Clinical Institute (Bucharest): Dana R Tomescu, Alexandra Marcu; Emergency Clinical County Hospital Timisoara (Timisoara): Ovidiu H Bedreag, Marius Papurica; Elias University Emergency Hospital (Bucharest): Dan E Corneci, Silvius loan Negoita

Russian Federation: University Hospital (Kemerovo): Evgeny Grigoriev; Krasnoyarsk Regional Hospital, Krasnoyarsk State Medical University (Krasnoyarsk): Alexey I Gritsan, Andrey A Gazenkampf

Saudi Arabia: GICU of PSMMC (Riyadh): Ghaleb Almekhlafi, Mohamad M Albarrak; SICU of PSMMC (Riyadh): Ghanem M Mustafa; King Faisal Hospital And Research Center (Riyadh): Khalid A Maghrabi, Nawal Salahuddin; King Fahad Hospital (Baha): Tharwat M Aisa; King Abdulaziz Medical City (Riyadh): Ahmed S Al Jabbary, Edgardo Tabhan; King Abdulaziz Medical City (Riyadh): Yaseen M Arabi; King Abdulaziz Medical City (Riyadh): Yaseen M Arabi, Olivia A Trinidad; King Abdulaziz Medical City (Riyadh): Hasan M Al Dorzi, Edgardo E Tabhan

South Africa: Charlotte Maxeke Johannesburg Academic Hospital

(Johannesburg): Stefan Bolon, Oliver Smith

Spain: Hospital Sant Pau (Barcelona): Jordi Mancebo, Hernan Aguirre-Bermeo: Hospital Universitari Bellvitge (L Hospitalet De Llobregat (Barcelona)): Juan C Lopez-Delgado, Francisco Esteve; Hospital Son Llatzer (Palma De Mallorca): Gemma Rialp, Catalina Forteza; Sabadell Hospital, CIBER Enfermedades Respiratorias (Sabadell): Candelaria De Haro, Antonio Artigas; Hospital Universitario Central De Asturias (Oviedo): Guillermo M Albaiceta, Sara De Cima-Iglesias; Complejo Hospitalario Universitario A Coruña (A Coruña): Leticia Seoane-Quiroga, Alexandra Ceniceros-Barros; Hospital Universitario Miguel Servet (Zaragoza): Antonio L Ruiz-Aguilar, Luis M Claraco-Vega; Morales Meseguer University Hospital (Murcia): Juan Alfonso Soler, Maria del Carmen Lorente; Hospital Universitario del Henares (Coslada): Cecilia Hermosa, Federico Gordo; Complejo Asistencial De Palencia. Hospital Rio Carrión (Palencia): Miryam - PrietoGonzález, Juan B López-Messa; Fundación Jiménez Díaz (Madrid): Manuel P Perez, Cesar P Perez; Hospital Clínico Universitario Lozano Blesa (Zaragoza): Raquel Montoiro Allue; Hospital Verge de la Cinta (Tortosa): Ferran Roche-Campo, Marcos Ibañez-Santacruz; Hospital Universitario 12 De Octubre (Madrid): Susana - Temprano; Hospital Universitario Príncipe De Asturias (Alcalá De Henares, Madrid): Maria C Pintado, Raul De Pablo; Hospital Universitari Germans Trias I Pujol (Badalona): Pilar Ricart Aroa Gómez; Hospital Universitario Arnau De Vilanova De Lleida (Lleida): Silvia Rodriguez Ruiz, Silvia Iglesias Moles; Cst Terrassa (Barcelona): Ma Teresa Jurado, Alfons Arizmendi; Hospital Universitari Mútua Terrassa (Terrassa): Enrique A Piacentini; Hospital Universitario De Móstoles (Mostoles): Nieves Franco, Teresa
Honrubia; Complejo Asistencial De Salamanca (Salamanca): Meisy Perez Cheng, Elena Perez Losada; Hospital General Universitario De Ciudad Real (Ciudad Real): Javier - Blanco, Luis J Yuste; Torrecardenas (Almeria): Cecilia Carbayo-Gorriz, Francisca G Cazorla-Barranquero; Hospital Universitario Donostia (San Sebastian): Javier G Alonso, Rosa S Alda; Hospital Universitario De Torrejón (Madrid): Ángela Algaba, Gonzalo Navarro; Hospital Universitario De La Princesa (Madrid): Enrique Cereijo, Esther Diaz-Rodriguez; Hospital Universitario Lucus Augusti (Lugo): Diego Pastor Marcos, Laura Alvarez Montero; Hospital Universitario Santa Lucia (Cartagena): Luis Herrera Para, Roberto Jimenez Sanchez; Hospital Universitario Severo Ochoa, Leganes (Madrid): Miguel Angel Blasco Navalpotro, Ricardo Diaz Abad; University Hospital Of Ntra. Sra. De Candelaria (Santa Cruz De Tenerife): Raquel Montiel Gonz á lez, D á cil Parrilla Toribio; Hospital Universitario Marques De Valdecilla (Santander): Alejandro G Castro, Maria Jose D Artiga; Hospital Infanta Cristina (Parla, Madrid): Oscar Penuelas; Hospital General De Catalunya (Sant Cugat Del Valles): Tomas P Roser, Moreno F Olga; San Pedro De Alcántara (Cáceres): Elena Gallego Curto, Rocío Manzano Sánchez; Sant Joan De Reus (Reus): Vallverdu P Imma, Garcia M Elisabet; Hospital Joan XXIII (Tarragona): Laura Claverias, Monica Magret; Hospital Universitario De Getafe (Madrid): Ana M Pellicer, Lucia L Rodriguez; Hospital Universitario Río Hortega (Valladolid): Jesús Sánchez-Ballesteros, Ángela González-Salamanca; Hospital Arquitecto Marcide (Ferrol, La Coruña): Antonio G Jimenez, Francisco P Huerta; Hospital General Universitario Gregorio Marañón (Madrid): Juan Carlos J Sotillo Diaz, Esther Bermejo Lopez; Hospital General De Segovia (Segovia): David D Llinares Moya, Alec A Tallet Alfonso; Hospital General Universitario Reina Sofia (Murcia): Palazon Sanchez Eugenio Luis, Palazon Sanchez Cesar; Complejo Hospitalario Universitario De Albacete (Albacete): Sánchez I Rafael, Corcoles G Virgilio; Hospital Infanta Elena (Valdemoro): Noelia N Recio

Sweden: Sahlgrenska University Hospital (Gothenburg): Richard O Adamsson, Christian C Rylander; Karolinska University Hospital (Stockholm): Bernhard Holzgraefe, Lars M Broman; Akademiska Sjukhuset Uppsala (Uppsala): Joanna Wessbergh, Linnea Persson; Vrinnevisjukhuset (Norrköping): Fredrik Schiöler, Hans Kedelv; Linkoping University Hospital (Linköping): Anna Oscarsson Tibblin, Henrik Appelberg; Skellefteå Lasarett (Skellefteå): Lars Hedlund, Johan Helleberg; Karolinska University Hospital Solna (Stockholm): Karin E Eriksson, Rita Glietsch; Umeå University Hospital (Umeå): Niklas Larsson, Ingela Nygren; Danderyd Hospital (Stockholm): Silvia L Nunes, Anna-Karin Morin; Lund University Hospital (Lund): Thomas Kander, Anne Adolfsson Switzerland: Chuv (Centre Hospitalier Universitaire Vaudois) (Lausanne): Lise Piquilloud; Hôpital neuchâtelois - La Chaux-De-Fonds (La Chaux-De-Fonds): Hervé O. Zender, Corinne Leemann-Refondini

Tunisia: Hopital Taher Sfar Mahdia (Mahdia): Souheil Elatrous; University Hospital Farhat Hached Sousse (Sousse): Slaheddine Bouchoucha, Imed Chouchene; CHU F.Bourguiba (Monastir): Islem Ouanes; Mongi Slim University Hospital, La Marsa (La Marsa): Asma Ben Souissi, Salma Kamoun Turkey: Cerrahpasa Medical Faculty Emergency Intensive Care Unit (Istanbul): Oktay Demirkiran; Cerrahpasa Medical Faculty Sadi Sun Intensive Care Unit (Istanbul): Mustafa Aker, Emre Erbabacan; Uludag University Medical Faculty (Bursa): Ilkay Ceylan, Nermin Kelebek Girgin; Ankara University Faculty of Medicine, Reanimation 3nd level ICU (Ankara): Menekse Ozcelik, Necmettin Ünal; Ankara University Faculty of Medicine, 2nd level ICU-postoperative ICU (Ankara): Basak Ceyda Meco; Istanbul Kartal Egitim Ve Arastirma Hastanesi (Istanbul): Onat O Akyol, Suleyman S Derman

UK: Papworth Hospital (Cambridge): Barry Kennedy, Ken Parhar; Royal Glamorgan Hospital (Llantrisant): Latha Srinivasa; Royal Victoria HospitalBelfast (Belfast): Lia McNamee, Danny McAuley; Jack Steinberg ICU of the King's College (London): Phil Hopkins, Clare Mellis; Frank Stansil ICU of the King's College Hospital (London): Vivek Kakar; Liver ICU of the King's College (London): Dan Hadfield; Christine Brown ICU of the King's College (London): Andre Vercueil; West Suffolk Hospital (Bury St Edmunds): Kaushik Bhowmick, Sally K Humphreys; Craigavon Area Hospital (Portadown): Andrew Ferguson, Raymond Mckee; Barts Health NHS Trust, Whipps Cross Hospital (Leytonstone): Ashok S Raj, Danielle A Fawkes; Kettering General Hospital, Foundation NHS Trust (Northamptonshire): Philip Watt, Linda Twohey; Barnet General Hospital (Barnet): Rajeev R JhaMatthew Thomas, Alex Morton, Varsha Kadaba; Rotherham General Hospital (Rotherham): Mark J Smith, Anil P Hormis; City Hospital, (Birmingham): Santhana G Kannan, Miriam Namih; Poole Hospital NHS Foundation Trust (Poole): Henrik Reschreiter, Julie Camsooksai; Weston General Hospital (Weston-Super-Mare): Alek Kumar, Szabolcs Rugonfalvi; Antrim Area Hospital (Antrim): Christopher Nutt, Orla O'Neill; Aintree University Hospital (Liverpool): Colette Seasman, Ged Dempsey; Northern General Hospital (Sheffield): Christopher J Scott, Helen E Ellis; John 
Radcliffe Hospital (Oxford): Stuart Mckechnie, Paula J Hutton; St Georges Hospital (London): Nora N Di Tomasso, Michela N Vitale; Hillingdon Hospital (Uxbridge): Ruth 0 Griffin, Michael N Dean; The Royal Bournemouth \& Christchurch NHS Foundation Trust (Bournemouth, Dorset): Julius H Cranshaw, Emma L Willett; Guys And St Thomas NHS Foundation Trust (London): Nicholas Ioannou, Gstt Severe Respiratory Failure Service; Whittington Hospital (London): Sarah Gillis; Wexham Park Hospital (Slough): Peter Csabi; Western General Hospital (Edinburgh): Rosaleen Macfadyen, Heidi Dawson; Royal Preston Hospital (Preston): Pieter D Preez, Alexandra J Williams; Brighton And Sussex University Hospitals NHS Trust (Brighton): Owen Boyd, Laura Ortiz-Ruiz De Gordoa; East And North Herts NHS Trust (Stevenage): Jon Bramall, Sophie Symmonds; Barnsley Hospital (Barnsley): Simon K Chau, Tim Wenham; Prince Charles Hospital (Merthyr Tydfil): Tamas Szakmany, Piroska Toth-Tarsoly; University Hospital Of South Manchester NHS Foundation Trust (Manchester): Katie H McCalman, Peter Alexander; Harrogate District Hospital (Harrogate): Lorraine Stephenson, Thomas Collyer; East And North Herts NHS Trust (Welwyn Garden City): Rhiannon Chapman, Raphael Cooper; Western Infirmary (Glasgow): Russell M Allan, Malcolm Sim; Dumfries And Galloway Royal Infirmary (Dumfries): David W Wrathall, Donald A Irvine; Charing Cross Hospital (London): Kim S Zantua, John C Adams; Worcestershire Royal Hospital (Worcester): Andrew J Burtenshaw, Gareth P Sellors; Royal Liverpool University Hospital (Liverpool): Ingeborg D Welters, Karen E Williams; Royal Alexandra Hospital (Glasgow): Robert J Hessell, Matthew G Oldroyd; Morriston Hospital (Swansea): Ceri E Battle, Suresh Pillai; Frimley Park Hospital (Frimley): Istvan Kajtor, Mageswaran Sivashanmugavel; Altnagelvin Hospital (Derry): Sinead C O'Kane, Adrian Donnelly; Buckinghamshire Healthcare NHS Trust (High Wycombe, Buckinghamshire): Aniko D Frigyik, Jon P Careless; Milton Keynes Hospital (Milton Keynes): Martin M May, Richard Stewart; Ulster Hospital (Belfast): T John Trinder, Samantha J Hagan; University Hospital of Wales (Cardiff): Matt P Wise, Jade M Cole; Freeman Hospital (Newcastle Upon Tyne): Caroline C MacFie, Anna T Dowling

Uruguay: Hospital Español (Montevideo): Javier Hurtado, Nicolás Nin; Cudam (Montevideo): Javier Hurtado; Sanatorio Mautone (Maldonado): Edgardo Nuñez; Sanatorio Americano (Montevideo): Gustavo Pittini, Ruben Rodriguez; Hospital De Clínicas (Montevideo): María C Imperio, Cristina Santos; Circulo Católico Obreros Uruguay- Sanatorio JPII (Montevido): Ana G. França, Alejandro EBEID; CASMU (Montevideo): Alberto Deicas, Carolina Serra USA: Saint Louis University Hospital (St.Louis): Aditya Uppalapati, Ghassan Kamel; Beth Israel Deaconess Medical Center (Boston): Valerie M BannerGoodspeed, Jeremy R Beitler; Memorial Medical Center (Springfield): Satyanarayana Reddy Mukkera, Shreedhar Kulkarni; Massachusetts General Hospital (Boston): Jarone Lee, Tomaz Mesar; University Of Cincinnati Medical Center (Cincinnati): John O Shinn 3rd, Dina Gomaa; Massachusetts General Hospital (Boston): Christopher Tainter, Jarone Lee; Massachusetts General Hospital (Boston): Tomaz Mesar, Jarone Lee; R Adams Cowley Shock Trauma Center (Baltimore): Dale J Yeatts, Jessica Warren; Intermountain Medical Center (Murray, Utah): Michael J Lanspa, Russel R Miller; Intermountain Medical Center (Murray, Utah): Colin K Grissom, Samuel M Brown; Mayo Clinic (Rochester): Philippe R Bauer; North Shore Medical Center (Salem): Ryan J Gosselin, Barrett T Kitch; Albany Medical Center (Albany): Jason E Cohen, Scott H Beegle; John H Stoger Hospital Of Cook County (Chicago, II): Renaud M Gueret, Aiman Tulaimat; Albany Medical Center (Albany): Shazia Choudry; University of Alabama at Birmingham (UAb) (Birmingham, AL): William Stigler, Hitesh Batra; Duke University Hospital (Durham): Nidhi G Huff; lowa Methodist Medical Center (Des Moines, lowa): Keith D Lamb, Trevor W Oetting; Surgical \& Neurosciences Intensive Care Unit of the University Of lowa Hospitals And Clinics (lowa City, lowa): Nicholas M Mohr, Claine Judy; Medical Center of Louisiana at New Orleans (New Orleans, Louisiana): Shigeki Saito, Fayez M Kheir; Tulane University (New Orleans): Fayez Kheir; Critical Care Unit of the University Of lowa Hospitals And Clinics (lowa City, lowa): Adam B Schlichting, Angela Delsing; University Of California, San Diego Medical Center (San Diego, Ca): Daniel R Crouch, Mary Elmasri; Uc San Diego Thornton Hospital (La Jolla): Daniel R Crouch, Dina Ismail; University Hospital (Cincinnati): Kyle R Dreyer, Thomas C Blakeman; University Hospital (Cincinnati): Kyle R Dreyer, Dina Gomaa; Tower 3B Medical ICU of Brigham and Women's Hospital (Boston): Rebecca M Baron, Carolina Quintana Grijalba; Tower 8C Burn/Trauma ICU of Brigham and Women's Hospital (Boston): Peter C Hou; Tower 8D Surgical ICU of Brigham and Women's Hospital (Boston): Raghu Seethala; Tower $9 \mathrm{C}$
Neurosurgical ICU of Brigham and Women's Hospital (Boston): Imo Aisiku; Tower 9D Neurological ICU of Brigham and Women's Hospital (Boston): Galen Henderson; Tower 11C Thoracic ICU of Brigham and Women's Hospital (Boston): Gyorgy Frendl; Shapiro 6W Cardiac Surgery ICU of Brigham and Women's Hospital (Boston): Sen-Kuang Hou; Shapiro 9E Coronary Care Unit of Brigham and Women's Hospital (Boston): Robert L Owens, Ashley Schomer

Serbia: Clinical Center of Serbia (Belgrade): Vesna Bumbasirevic, Bojan Jovanovic; Military Medical Academy (Belgrade): Maja Surbatovic, Milic Veljovic

\section{Authors' contributions}

$J L, G B$, and $L B$ conceived of and designed this study, interpreted the data, drafted the manuscript, and revised the manuscript for important intellectual content. FM, TP, EF, and ER contributed to the acquisition of data, conducted data cleaning, analyzed the data, interpreted the data, and revised the manuscript for important intellectual content. BM, AP, RP, and FV interpreted the data and revised the manuscript for important intellectual content. All of the authors reviewed, discussed, and approved the final manuscript.

\section{Funding}

This work was funded and supported by the European Society of Intensive Care Medicine (ESICM), Brussels, Belgium, by St Michael's Hospital, Toronto, Canada, and by the University of Milan-Bicocca, Monza, Italy.

\section{Availability of data and materials}

Available upon request

\section{Ethics approval and consent to participate}

All participating ICUs obtained ethics committee approval and obtained either patient consent or ethics committee waiver of consent in LUNG SAFE study. The study protocol was also reviewed and approved by the ethics committee of Mito Kyodo General Hospital, University of Tsukuba Hospital Mito Medical Center, Japan.

\section{Consent for publication}

Not applicable

\section{Competing interests}

The authors declare that they have no competing interests.

\section{Author details}

${ }^{1}$ Research Center on Public Health, School of Medicine and Surgery, University of Milano-Bicocca, Monza, Italy. ${ }^{2}$ Scientific Institute for Research, Hospitalization and Health Care, IRCCS Multimedica, Sesto San Giovanni, Milan, Italy. ${ }^{3}$ Department of Medicine and Surgery, University of Milano-Bicocca, Monza, Italy. ${ }^{4}$ Anaesthesia and Intensive Care Medicine, School of Medicine, National University of Ireland Galway, Galway, Ireland. ${ }^{5}$ Regenerative Medicine Institute (REMEDI) at CÚRAM Centre for Research in Medical Devices, Biomedical Sciences Building, National University of Ireland Galway, Galway, Ireland. ${ }^{6}$ Keenan Research Centre for Biomedical Science, St Michael's Hospital, Toronto, Canada. ${ }^{7}$ Department of Critical Care Medicine, St Michael's Hospital, Toronto, Canada. ${ }^{8}$ Interdepartmental Division of Critical Care Medicine, University of Toronto, Toronto, Canada. ${ }^{9}$ Institute of Health Policy, Management and Evaluation, University of Toronto, Toronto, Canada. ${ }^{10}$ Nephrology, School of Medicine, National University of Ireland Galway, Galway, Ireland. ${ }^{11}$ Department of Biomedical Sciences, Humanitas University, Pieve Emanuele (Milan), Italy. ${ }^{12}$ Humanits clinical and research center IRCCS, Rozzano (Milan), Italy. ${ }^{13}$ Intensive Care Unit, John Hunter Hospital, New Lambton Heights, NSW, Australia. ${ }^{14}$ School of Medicine and Public Health, University of Newcastle, Newcastle, Australia. ${ }^{15}$ Department of Emergency and Intensive Care, San Gerardo Hospital, Monza, Italy. ${ }^{16}$ Department of Medicine, University Health Network and Sinai Health System, Toronto, Canada. ${ }^{17}$ Intensive Care Unit, The Canberra Hospital and Australian National University, Canberra, Australia. 


\section{Received: 6 December 2019 Accepted: 6 March 2020}

Published online: 31 March 2020

\section{References}

1. Ranieri VM, Rubenfeld GD, Thompson BT, Ferguson ND, Caldwell E, Fan E, Camporota L, Slutsky AS. Acute respiratory distress syndrome: the Berlin definition. JAMA. 2012;307(23):2526-33.

2. Maclntyre NR. Tissue hypoxia: implications for the respiratory clinician. Respir Care. 2014;59(10):1590-6.

3. Itagaki T, Nakano Y, Okuda N, Izawa M, Onodera M, Imanaka H, Nishimura M. Hyperoxemia in mechanically ventilated, critically ill subjects: incidence and related factors. Respir Care. 2015;60(3):335-40.

4. de Graaff AE, Dongelmans DA, Binnekade JM, de Jonge E. Clinicians' response to hyperoxia in ventilated patients in a Dutch ICU depends on the level of FiO2. Intensive Care Med. 2011:37(1):46-51.

5. Helmerhorst HJ, Schultz MJ, van der Voort PH, Bosman RJ, Juffermans NP, de Jonge $E$, van Westerloo DJ. Self-reported attitudes versus actual practice of oxygen therapy by ICU physicians and nurses. Ann Intensive Care. 2014;4:23.

6. Brenner M, Stein D, Hu P, Kufera J, Wooford M, Scalea T. Association between early hyperoxia and worse outcomes after traumatic brain injury. Arch Surg. 2012;147(11):1042-6.

7. Rincon F, Kang J, Vibbert M, Urtecho J, Athar MK, Jallo J. Significance of arterial hyperoxia and relationship with case fatality in traumatic brain injury: a multicentre cohort study. J Neurol Neurosurg Psychiatry. 2014;85(7): 799-805.

8. Davis DP, Meade W, Sise MJ, Kennedy F, Simon F, Tominaga G, Steele J, Coimbra R. Both hypoxemia and extreme hyperoxemia may be detrimental in patients with severe traumatic brain injury. J Neurotrauma. 2009;26(12): 2217-23.

9. Alali AS, Temkin N, Vavilala MS, Lele AV, Barber J, Dikmen S, Chesnut RM. Matching early arterial oxygenation to long-term outcome in severe traumatic brain injury: target values. J Neurosurg. 2019;132(2):537-44.

10. O'Briain D, Nickson C, Pilcher DV, Udy AA. Early Hyperoxia in patients with traumatic brain injury admitted to intensive Care in Australia and New Zealand: a retrospective multicenter cohort study. Neurocrit Care. 2018; 29(3):443-51.

11. Rincon F, Kang J, Maltenfort M, Vibbert M, Urtecho J, Athar MK, Jallo J, Pineda CC, Tzeng D, McBride W, et al. Association between hyperoxia and mortality after stroke: a multicenter cohort study. Crit Care Med. 2014;42(2): $387-96$

12. Stub D, Smith K, Bernard S, Nehme Z, Stephenson M, Bray JE, Cameron P, Barger B, Ellims AH, Taylor AJ, et al. Air versus oxygen in ST-segmentelevation myocardial infarction. Circulation. 2015;131(24):2143-50.

13. Kilgannon JH, Jones AE, Shapiro NI, Angelos MG, Milcarek B, Hunter K, Parrillo JE, Trzeciak S. Emergency medicine shock research network I: association between arterial hyperoxia following resuscitation from cardiac arrest and in-hospital mortality. JAMA. 2010;303(21):2165-71.

14. Janz DR, Hollenbeck RD, Pollock JS, McPherson JA, Rice TW. Hyperoxia is associated with increased mortality in patients treated with mild therapeutic hypothermia after sudden cardiac arrest. Crit Care Med. 2012; 40(12):3135-9.

15. Kilgannon JH, Jones AE, Parrillo JE, Dellinger RP, Milcarek B, Hunter K, Shapiro NI, Trzeciak S. Emergency medicine shock research network I: relationship between supranormal oxygen tension and outcome after resuscitation from cardiac arrest. Circulation. 2011;123(23):2717-22.

16. Roberts BW, Kilgannon JH, Hunter BR, Puskarich MA, Pierce L, Donnino M, Leary $\mathrm{M}$, Kline JA, Jones AE, Shapiro NI, et al. Association between early hyperoxia exposure after resuscitation from cardiac arrest and neurological disability: a prospective multi-center protocol-directed cohort study. Circulation. 2018;137:2114-24

17. Ebner F, Ullen S, Aneman A, Cronberg T, Mattsson N, Friberg H, Hassager C, Kjaergaard J, Kuiper M, Pelosi P, et al. Associations between partial pressure of oxygen and neurological outcome in out-of-hospital cardiac arrest patients: an explorative analysis of a randomized trial. Crit Care. 2019;23(1):30.

18. Bak Z, Sjoberg F, Rousseau A, Steinvall I, Janerot-Sjoberg B. Human cardiovascular dose-response to supplemental oxygen. Acta Physiol (Oxf). 2007;191(1):15-24

19. Reinhart K, Spies CD, Meier-Hellmann A, Bredle DL, Hannemann L, Specht M, Schaffartzik W. N-acetylcysteine preserves oxygen consumption and gastric mucosal pH during hyperoxic ventilation. Am J Respir Crit Care Med. 1995;151(3 Pt 1):773-9.
20. McNulty PH, Robertson BJ, Tulli MA, Hess J, Harach LA, Scott S, Sinoway LI. Effect of hyperoxia and vitamin $\mathrm{C}$ on coronary blood flow in patients with ischemic heart disease. J Appl Physiol (1985). 2007;102(5):2040-5.

21. Brueckl C, Kaestle S, Kerem A, Habazettl H, Krombach F, Kuppe H, Kuebler WM. Hyperoxia-induced reactive oxygen species formation in pulmonary capillary endothelial cells in situ. Am J Respir Cell Mol Biol. 2006;34(4):453-63.

22. Mantell LL, Lee PJ. Signal transduction pathways in hyperoxia-induced lung cell death. Mol Genet Metab. 2000;71(1-2):359-70.

23. Asfar P, Schortgen F, Boisrame-Helms J, Charpentier J, Guerot E, Megarbane B, Grimaldi D, Grelon F, Anguel N, Lasocki S, et al. Hyperoxia and hypertonic saline in patients with septic shock (HYPERS2S): a two-by-two factorial, multicentre, randomised, clinical trial. Lancet Respir Med. 2017;5(3):180-90.

24. Girardis M, Busani S, Damiani E, Donati A, Rinaldi L, Marudi A, Morelli A, Antonelli $M$, Singer M. Effect of conservative vs conventional oxygen therapy on mortality among patients in an intensive care unit: the oxygenICU randomized clinical trial. JAMA. 2016;316(15):1583-9.

25. ICU-ROX Investigators, the A, New Zealand Intensive Care Society Clinical Trials G, Mackle D, Bellomo R, Bailey M, Beasley R, Deane A, Eastwood G, Finfer $S$ et al: Conservative oxygen therapy during mechanical ventilation in the ICU. N Engl J Med 2019 [ahead of print] doi: https://doi.org/10.1056/ NEJMoa1903297.

26. Young P, Mackle D, Bellomo R, Bailey M, Beasley R, Deane A, Eastwood G, Finfer S, Freebairn R, King $V$ et al: Conservative oxygen therapy for mechanically ventilated adults with sepsis: a post hoc analysis of data from the intensive care unit randomized trial comparing two approaches to oxygen therapy (ICU-ROX). Intensive Care Med 2019 [ahead of print] doi: https://doi.org/10.1007/s00134-019-05857-x.

27. Aggarwal NR, Brower RG, Hager DN, Thompson BT, Netzer G, Shanholtz C, Lagakos A, Checkley W. National Institutes of Health acute respiratory distress syndrome network I: oxygen exposure resulting in arterial oxygen tensions above the protocol goal was associated with worse clinical outcomes in acute respiratory distress syndrome. Crit Care Med. 2018;46(4):517-24.

28. Yamada M, Kubo H, Kobayashi S, Ishizawa K, Sasaki H. Interferon-gamma: a key contributor to hyperoxia-induced lung injury in mice. Am J Physiol Lung Cell Mol Physiol. 2004;287(5):L1042-7.

29. Aggarwal NR, D'Alessio FR, Tsushima K, Files DC, Damarla M, Sidhaye VK, Fraig MM, Polotsky W, King LS. Moderate oxygen augments lipopolysaccharide-induced lung injury in mice. Am J Physiol Lung Cell Mol Physiol. 2010;298(3):L371-81.

30. Baleeiro CE, Wilcoxen SE, Morris SB, Standiford TJ, Paine R 3rd. Sublethal hyperoxia impairs pulmonary innate immunity. J Immunol. 2003;171(2):955-63.

31. Helmerhorst HJF, Schouten LRA, Wagenaar GTM, Juffermans NP, Roelofs J, Schultz MJ, de Jonge E, van Westerloo DJ. Hyperoxia provokes a time- and dose-dependent inflammatory response in mechanically ventilated mice, irrespective of tidal volumes. Intensive Care Med Exp. 2017;5(1):27.

32. Sinclair SE, Altemeier WA, Matute-Bello G, Chi EY. Augmented lung injury due to interaction between hyperoxia and mechanical ventilation. Crit Care Med. 2004;32(12):2496-501.

33. Li LF, Liao SK, Ko YS, Lee CH, Quinn DA. Hyperoxia increases ventilatorinduced lung injury via mitogen-activated protein kinases: a prospective, controlled animal experiment. Crit Care. 2007;11(1):R25.

34. Bellani G, Laffey JG, Pham T, Fan F, Brochard L, Esteban A, Gattinoni L, van Haren F, Larsson A, McAuley DF, et al. Epidemiology, patterns of care, and mortality for patients with acute respiratory distress syndrome in intensive care units in 50 countries. JAMA. 2016;315(8):788-800.

35. Bellani G, Laffey JG, Pham T, Madotto F, Fan E, Brochard L, Esteban A, Gattinoni L, Bumbasirevic V, Piquilloud L, et al. Non-invasive ventilation of patients with acute respiratory distress syndrome: insights from the LUNG SAFE study. Am J Respir Crit Care Med. 2017;195(1):67-77.

36. Laffey JG, Bellani G, Pham T, Fan E, Madotto F, Bajwa EK, Brochard L, Clarkson K, Esteban A, Gattinoni L, et al. Potentially modifiable factors contributing to outcome from acute respiratory distress syndrome: the LUNG SAFE study. Intensive Care Med. 2016;42(12):1865-76.

37. McNicholas BA, Madotto F, Pham T, Rezoagli E, Masterson CH, Horie S, Bellani G, Brochard L, Laffey JG, Investigators LS, et al. Demographics, management and outcome of females and males with acute respiratory distress syndrome in the LUNG SAFE prospective cohort study. Eur Respir J. 2019;54(4). https:// doi.org/10.1183/13993003.00609-2019.

38. Kallstrom TJ. American Association for Respiratory C: AARC clinical practice guideline: oxygen therapy for adults in the acute care facility-2002 revision \& update. Respir Care. 2002:47(6):717-20. 
39. Ventilation with lower tidal volumes as compared with traditional tidal volumes for acute lung injury and the acute respiratory distress syndrome. The Acute Respiratory Distress Syndrome Network. N Engl J Med. 2000, 342(18):1301-1308.

40. O'Driscoll BR, Howard LS, Bucknall C, Welham SA, Davison AG, British Thoracic S. British Thoracic Society emergency oxygen audits. Thorax. 2011;66(8):734-5.

41. O'Driscoll BR, Howard LS, Earis J, Mak V. British Thoracic Society Emergency Oxygen Guideline G, Group BTSEOGD: BTS guideline for oxygen use in adults in healthcare and emergency settings. Thorax. 2017;72(Suppl 1):ii1-iig0.

42. Davis WB, Rennard SI, Bitterman PB, Crystal RG. Pulmonary oxygen toxicity. Early reversible changes in human alveolar structures induced by hyperoxia. N Engl J Med. 1983;309(15):878-83.

43. Kapanci Y, Tosco R, Eggermann J, Gould VE. Oxygen pneumonitis in man., light- and electron-microscopic morphometric studies. Chest. 1972;62(2): $162-9$.

44. de Jonge E, Peelen L, Keiizers PJ, Joore H, de Lange D, van der Voort PH, Bosman RJ, de Waal RA, Wesselink R, de Keizer NF. Association between administered oxygen, arterial partial oxygen pressure and mortality in mechanically ventilated intensive care unit patients. Crit Care. 2008;12(6): R156.

45. Helmerhorst HJ, Arts DL, Schultz MJ, van der Voort PH, Abu-Hanna A, de Jonge $E$, van Westerloo DJ. Metrics of arterial Hyperoxia and associated outcomes in critical care. Crit Care Med. 2017;45(2):187-95.

46. Aboab J, Louis B, Jonson B, Brochard L. Relation between PaO2/FIO2 ratio and FIO2: a mathematical description. Intensive Care Med. 2006;32(10): 1494-7.

\section{Publisher's Note}

Springer Nature remains neutral with regard to jurisdictional claims in published maps and institutional affiliations.

Ready to submit your research? Choose BMC and benefit from:

- fast, convenient online submission

- thorough peer review by experienced researchers in your field

- rapid publication on acceptance

- support for research data, including large and complex data types

- gold Open Access which fosters wider collaboration and increased citations

- maximum visibility for your research: over $100 \mathrm{M}$ website views per year

At $\mathrm{BMC}$, research is always in progress.

Learn more biomedcentral.com/submissions 